\title{
The near-quantitative sampling of genomic DNA from various food-borne Eubacteria
}

\author{
Peter Irwin*, Ly Nguyen, Yiping He, George Paoli, Andrew Gehring and Chin-Yi Chen
}

\begin{abstract}
Background: The disruption of the bacterial cell wall plays an important part in achieving quantitative extraction of DNA from Eubacteria essential for accurate analyses of genetic material recovered from environmental samples.

Results: In this work we have tested a dozen commercial bacterial genomic DNA extraction methodologies on an average of $7.70 \times 10^{6}( \pm 9.05 \%), 4.77 \times 10^{8}( \pm 31.0 \%)$, and $5.93 \times 10^{8}( \pm 4.69 \%)$ colony forming units (CFU) associated with 3 cultures ( $n=3$ ) each of Brochothrix thermosphacta (Bt; Gram-positive), Shigella sonnei (Ss; Gram-negative), and Escherichia coli O79 (EC; Gram-negative). We have utilized real-time PCR (qPCR) quantification with two specific sets of primers associated with the $16 \mathrm{~S}$ rRNA "gene" to determine the number of copies $\mathrm{CFU}^{-1}$ by comparing the unknown target DNA qPCR results with standards for each primer set. Based upon statistical analyses of our results, we determined that the Agencourt Genfind v2, High Pure PCR Template Prep Kit, and Omnilyse methods consistently provided the best yield of genomic DNA ranging from 141 to 934, 8 to 21, and 16 to $2716 \mathrm{~S} \mathrm{rDNA}$ copies CFU ${ }^{-1}$ for $B t, S S$, and Ec. If one assumes 6-7 copies of the 16S rRNA gene per genome, between 1 and 3 genomes per actively dividing cell and $\geq 100$ cells $\mathrm{CFU}^{-1}$ for $B t$ (found to be a reasonable assumption using an optical method expounded upon herein) or between 1 and 2 cells $\mathrm{CFU}^{-1}$ for either $S S$ or $E C$, then the Omnilyse procedure provided nearly quantitative extraction of genomic DNA from these isolates (934 \pm 19.9 copies CFU ${ }^{-1}$ for Bt; $20.8 \pm 2.68$ copies CFU ${ }^{-1}$ for Ss; $26.9 \pm 3.39$ copies CFU $^{-1}$ for Ec). The Agencourt, High Pure, and Omnilyse technologies were subsequently assessed using 5 additional Gram-positive and 10 Gram-negative foodborne isolates $(n=3)$ using a set of "universal" 165 rDNA primers.

Conclusion: Overall, the most notable DNA extraction method was found to be the Omnilyse procedure which is a "bead blender" technology involving high frequency agitation in the presence of zirconium silicate beads.
\end{abstract}

\section{Background}

It is apparent that a quantitative understanding of microbial populations in various habitats can not be accomplished utilizing traditional culture methods [1] inasmuch as "unculturable" components may greatly outnumber all others [2,3]. The term unculturable is taken [4] to simply mean that current technology/methods do not permit the growth of the particular organism in vitro yet these same organisms may thrive, or at least survive, in their native habitat. Obviously organisms which are moribund or injured are also likely to be unculturable. Even when the organisms in question can be propagated, they are liable to be analytically under-represented using most plate

\footnotetext{
*Correspondence: Peter.Irwin@ars.usda.gov

Agricultural Research Service, U. S. Department of Agriculture, Molecular Characterization of Foodborne Pathogens Research Unit, Eastern Regional Research Center, 600 East Mermaid Lane, Wyndmoor, PA 19038, USA
}

counting methods [5]. One way to enumerate microbial populations ex colliquia (literally, from [out of] the drain [or gutter]) is by means of a quantitative metagenomic analysis (i.e., a sequence analysis of all the genetic material sampled from the "environment" for identification purposes) [6] given that the metagenome includes all organisms: culturable, viable but not culturable $[4,7,8]$, as well as moribund/dead cells.

The disruption of the cell wall envelope [9] is one of the most important aspects of quantitative metagenomic analysis since the total isolation of DNA from all Eubacteria is required. These "true bacteria" consist of cells bounded by a cytoplasmic lipid membrane and either a thick peptidoglycan, also known as murein [10], layer (Gram-positive bacteria) or a thin peptidoglycan stratum layered between an inner and outer membrane (Gram-negative bacteria). This outer membrane contains lipopolysaccharides (LPS) 
which are made up of lipid A (the inner-most of three regions, typically a phosphorylated glucosamine disaccharide with multiple fatty acid side-chains), core polysaccharides (inner and outer core), and an O-antigen (3- to 8-mer oligosaccharides) [11].

There are numerous methods available for cell wall disruption including physical approaches (e.g., particlebased disruption, sonication) [9,12-15], biochemicalbased methods (e.g., detergents, enzymes, etc.) [13,16-21] or some combination of the two [18,22]. Quantitative extraction of DNA is particularly difficult for some bacteria, especially the Gram-positives, which seem to be somewhat more resistant to cell wall dissolution. The "prototypal" [13] cell disruption method was published in 1961 [23] and used an enzyme/detergent extraction and organic solvents to remove low molecular weight solutes whereupon recovery of the DNA from an aqueous solution was made using alcohol precipitation. For chemical disruption, different compounds have been used to dissolve and/or disrupt the bacterial cell wall: enzymes such as lysozyme and proteinase $\mathrm{K}$, detergents (e.g., SDS), as well as other chaotropic compounds (e.g., guanadinium isothiocyanate, phenol, urea) and chelating agents (e.g., EDTA). Physical techniques are often the first method of choice for cell disruption, and include mechanical disruption, liquid homogenization, sonication, freeze-thawing, and manual grinding. Regardless of what protocol one uses, the DNA which is extracted should be in a form that can be employed for immediate analysis [19].

Our research project's long-term goal is to quantitatively assess the relative composition of culturable [1] as well as all other forms of Eubacteria associated with meat processing, which can have as many as $10^{5}$ colony forming units (CFU) $\mathrm{cm}^{-2}$ [24] of area tested. Ultimately, we seek to determine if background organisms from such environments outgrow (at refrigeration temperatures) [1] and mask entrapped pathogens (e.g., in biofilms or other structures) from detection in processed foods. Upon reviewing recent literature [9,12,13,15-22], it was unclear which, if any, commercial cell lysis/DNA extraction kits extract genomic DNA quantitatively (i.e., with a near $100 \%$ efficiency). This latter statement is true because the subject tests were performed using a small, somewhat arbitrary, collection of techniques with little concern for statistical analyses of target DNA concentration. Additionally, primer-specific standards were not typically used to convert raw $q \mathrm{PCR}$ data to the total number of gene copies as a function of some standard cell concentration determinant such as most probable number (MPN), CFU or even microscopic cell counts. Thus, there is a need to investigate not only some recent next generation genomic DNA extraction procedures but also to do so using a more rigorous experimental design: i.e., true replication on the major source of microbiological variability using at least 3 clonal isolates derived from various food products and CFU-normalized target DNA concentration (i.e., DNA copies per CFU).

\section{Methods \\ Definitions \\ Indices}

$i=$ dilution index reserved for standard (stnd) $16 \mathrm{~S} r \mathrm{DNA}$ solutions used in $q \mathrm{PCR}(i=0,1,2, \cdots, 6)$; e.g., $0.1^{i=3}=$ 0.001 representing the dilution factor for three 1:10 dilutions of the stnd $16 \mathrm{~S} r \mathrm{DNA}$ sample (see $[T]_{i}=0$ below)

$j=$ dilution index reserved for unknown (unk) concentrations of genomic DNA from various extracts $(j=0,1,2,3) ;$ e.g., $0.1^{j=0}=1$ represents the undiluted sample; dilutions were performed from extracts in order to determine if raw $q \mathrm{PCR}$ efficiency data were within acceptable limits

$k=$ treatment (e.g., extraction method) index $(k=1,2, \cdots, m)$

$\ell=$ replicate or block index $(\ell=1,2, \cdots, n$; typically $n=3$ for all analysis of variance and multiple range tests, otherwise $n$ is variable)

$x_{k l}=$ the $k^{\text {th }}$ treatment (e.g., extraction or isolate) and $\ell^{\text {th }}$ replicate (e.g., block) of any set of experimental observations

\section{Abbreviations, symbols, \& equations}

$B t=$ Brochothrix thermosphacta (ground chicken isolate) [1]

Ss $=$ Shigella sonnei (ground chicken isolate) [1]

$E c=$ Escherichia coli O79 (whole chicken carcass isolate; O-type determined [2 July 2013] by the $E$. coli Reference Center, The Pennsylvania State University, University Park, PA 16802)

$R_{n}=$ normalized fluorescence signal with respect to cycle number $(C)$ which is typically sigmoidal in shape (i.e., $\partial R_{n} / \partial C$ has a near-Gaussian line-shape)

$C_{\partial \mathrm{i} \text { or j }}=$ extrapolated cycle number where $\partial^{2} R_{n} / \partial C^{2}=0$ for any $i^{\text {th }}$ or $j^{\text {th }}$ dilution

$[T]_{i}=i^{\text {th }}$ dilution of the standard target gene (copies $\left.\mu \mathrm{L}^{-1}\right)$ solution being amplified; $[T]_{i=0}=1.31 \times 10^{9} 16 \mathrm{~S}$ $r$ DNA copies $\mu \mathrm{L}^{-1}$ (Bt standard used for all Grampositive organisms), $1.06 \times 10^{9}$ copies $\mu \mathrm{L}^{-1}$ (Ss standard used for all Gram-negative organisms except $E c$ ), or $9.66 \times 10^{8}$ copies $\mu \mathrm{L}^{-1}$ (Ec standard) $\frac{\partial C_{\partial i}}{\partial \log _{10} T T_{i}}=$ change in $C_{\partial \mathrm{i}}$ with $\log _{10}[T]_{i}$ (ideally $\partial C_{\partial \mathrm{i}} / \partial \log _{\beta}[T]_{i}=-\log _{2} \beta ; \partial C_{\partial \mathrm{i}} / \partial \log _{\beta}[T]_{i}$ is always equivalent to $\partial C_{\partial \mathrm{i}} / \partial \log _{\beta}\left[\phi^{i}\right]$ and $\phi$ is the dilution factor; in this work $\phi=\beta^{-1}$ and $\beta$, the base of the logarithm, is always 10) [25] 
$\frac{\partial C_{\partial j}}{\partial \log _{10}\left[0.1^{j}\right]}=$ slope of $C_{\partial j}$ with respect to $\log _{10}\left[0.1^{j}\right]$ (i.e., concentration; $j=0,1,2$, or 3 )

$C_{\text {aintobs }}=$ intercept calculated from linear regression analysis of $C_{\partial i}$ as affected by changes in $\log _{10}[T]_{i}$ (ideally $\left.C_{\partial i n t o b s}=C_{\partial \mathrm{i}}+\log _{2}[T]_{i}\right)$ [25]

$C_{\text {วintpredicted } j}=C_{\partial j}-\left(\frac{\partial C_{\partial j}}{\partial \log _{10}\left[0.1^{\prime}\right]} \times \log _{10}\left[\left(1+\varepsilon_{i}\right)\left(C_{\partial \text { int obs }}-C_{\partial j}\right)\right]\right)$; predicted intercept for each $j^{\text {th }} u n k$ dilution; derivation of $C_{\text {zintpredicted } j \text { was fully developed }}$ elsewhere [25]

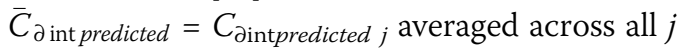

$\varepsilon_{\text {stnd }}=$ Taq DNA polymerase efficiency associated with standard dilutions $=-1+10^{\left(-\partial C_{\partial i} / \partial \log _{10}[T]_{i}\right)}$

$\varepsilon_{u n k}=\operatorname{Taq}$ DNA polymerase efficiency associated with unknown dilutions $=-1+10^{\left(-\partial C_{\partial j} / \partial \log _{10}\left[\phi^{j}\right]\right)^{-1}}$; poor $\varepsilon_{\text {unk }} \mathrm{s}\left(\right.$ e.g., $0.9 \geq \varepsilon_{\text {unk }} \geq 1.1$ ) are possible indicators of enzyme perturbation [26] by inhibitory substances in an extract

$[\mp]_{j}=$ traditional calculation of the unknown target gene DNA concentration (copies $\mu \mathrm{L}^{-1}$ of extract) for the $j^{\text {th }}$ dilution $=\left(1+\varepsilon_{\text {stnd }}\right)^{C_{\partial \text { intobs }}-C_{\partial} j}$

$[T]_{j}=j^{\text {th }}$ dilution of the corrected unknown DNA concentration (copies $\mu \mathrm{L}^{-1}$ of extract) $=$

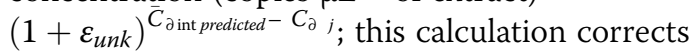
[25] for the fact that $\varepsilon_{\text {stnd }}$ sometimes is substantially different than $\varepsilon_{u n k}$ and is the value reported in all Tables; when $\varepsilon_{\text {stnd }} \sim \varepsilon_{u n k},[\mp]_{j} \sim[T]_{j}$ $\delta=$ organism concentration or density $\left(\mathrm{CFU} \mathrm{mL} \mathrm{m}^{-1}\right.$ ) $r$ RNA "gene" copies CFU ${ }^{-1}=[T]_{j=0}$ (in units of copies $\mu \mathrm{L}^{-1}$ of extract $) \times$ total $\mu \mathrm{L}$ of extract $\div$ CFUs in $1 \mathrm{~mL}$ of culture; the values of the total assay volume have been provided at the end of each extraction procedure (listed below). The average value $(\bar{x})$ of each biological replicate's CFU mL ${ }^{-1}$ are listed in all Tables \pm coefficients of variation $(C V=s \div \bar{x})$. Since all counting-based data have technical replicate variances $\sim \bar{x}$ (assuming the number of observations/dilution were appropriately high), we report $\bar{x}$ and $C V$ of the CFU $\mathrm{mL}^{-1}$ calculated from 2 or three 1:10 dilutions of the starting concentration.

$E E=$ extraction efficiency $=$ observed $16 \mathrm{~S} r$ DNA copies $\mathrm{CFU}^{-1} \div\left(16 \mathrm{~S} r \mathrm{RNA}\right.$ gene copies genome ${ }^{-1} \times$ genomes cell ${ }^{-1} \times$ cells $\mathrm{CFU}^{-1} \div$ plating efficiency); e.g., assuming 24 copies $\mathrm{CFU}^{-1} \div$ (7 copies

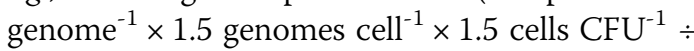
0.67 plating efficiency [67\%]), would result in a near $100 \%$ efficiency; gene copies genome ${ }^{-1}$ can vary between 1 and 14 but typically between 5 and 7; genomes cell ${ }^{-1}$ would probably vary between 1 and 3 but is dependent upon the rate of cell division; cells $\mathrm{CFU}^{-1}$ varies greatly depending on the organism but typically ranges between 1 and 2 for $S s, E c$, and Salmonella spp.; plating efficiency is a correction for losses on solid media (e.g., for organisms like $S s$ and $E c$, this term could vary between 50 and 100\%)

$\mathrm{SS}=$ sum of squares

$T M S=$ treatment mean square

"= $($ Treatment SS $/(m-1) "$

$E M S=$ error mean square

" $=($ Total SS $-($ Block SS + Treatment SS $)) /$

$((m-1) *(n-1)) "$

$F=\mathrm{F}$ statistic

"=TMS $/ E M S "$

$\bar{x}_{k}=x_{k} \div n$

"=AVERAGE $\left(x_{k 1}: x_{k n}\right) "$

$S E=$ experimental standard error

"= $(\mathrm{SQRT}(E M S) / n) "$

$P=$ the probability of rejecting the null hypothesis when it is true (i.e., when there is no relationship between two measured observations); means were characteristically taken to be "significantly different" when $P \leq 0.05$

$q_{P}=$ the "Studentized" range distribution tabulated in numerous statistics texts $[27,28]$ for a $P=0.01$ or 0.05

$t_{P}=$ "Student's $t$ " at probability $P$ " $=\operatorname{TINV}(P, n-2) "$

\section{Statistical analyses}

The covariance $\left(\sigma_{\eta_{1} \cdot \eta_{2}}^{2}\right)$ associated with an hypothetical set of variables $\eta_{1, l}$ and $\eta_{2, l}$ (each with $n$ replicates; e.g., $\partial C_{\partial \mathrm{i}} / \partial \log _{10}[T]_{i}, C_{\partial j}$, or $\left.[T]_{i}\right)$ was calculated using the Excel function " $=$ COVARIANCE.P $\left(\eta_{1,1}: \eta_{1, n}, \eta_{2,1}: \eta_{2, n}\right)$ " and the 2 variances, $\sigma_{\eta_{1}}^{2}$ and $\sigma_{\eta_{2}}^{2}$, were calculated using "= $\left(\operatorname{STDEV} \cdot \mathrm{P}\left(\eta_{1,1}: \eta_{1, n}\right)\right)^{\wedge} 2 ”$ and “ $=\left(\operatorname{STDEV} \cdot \mathrm{P}\left(\eta_{2,1}: \eta_{2, n}\right)\right)^{\wedge} 2 ”$. Identical results were obtained using the VarianceCovariance matrix $(2 \times 2)$ approach whereupon $\sigma_{\eta_{1} \cdot \eta_{2}}^{2}$ is equal to the two off-diagonal terms and $\sigma_{\eta_{1}}^{2}$ or $\sigma_{\eta_{2}}^{2}$ are the diagonal components. The statistical relevance of $\sigma_{\eta_{1} \cdot \eta_{2}}^{2}$ was calculated by testing the significance of $\rho_{\eta_{1} \cdot \eta_{2}}=\sigma_{\eta_{1} \cdot \eta_{2}}^{2} \times$ $\sqrt[-2]{\sigma_{\eta_{1}}^{2} \cdot \sigma_{\eta_{2}}^{2}}$ (i.e., the correlation coefficient) using a $t$-test (e.g., $\left.t_{\rho}=\left|\rho_{\eta_{1} \cdot \eta_{2}}\right| \times \sqrt{\frac{n-2}{1-\rho_{\eta_{1} \cdot \eta_{2}}^{2}}}\right)$ at some level of probability $P$. Determination of this probability-level was made by continuously changing (using Excel's Solver tool) this term in the Excel equation for $t_{P}$ until the TINV function matched that of $t_{\rho}$. Such tests can be important for some comparisons since they determine the statistical significance of a correlation of paired variables which are not necessarily a direct function of one another but which might vary together (i.e., non-randomly) because of subtle factors in the system being examined. All $\bar{x}$ values reported in figures/tables are presented $\pm(n-1)$-weighted 
standard deviations ( $s$; “ $=\operatorname{STDEV} \cdot S\left(x_{1,1}: x_{1, n}\right)$ )). One-way analyses of variance (ANOVA; always for $n=3$ ) operations were performed assuming a randomized complete block design [27] and means were separated based upon a "Tukey Multiple Range" analysis which is also known as the "Honestly Significant Difference" (HSD) Test [28]. All ANOVA calculations and our algorithm for $H S D$ are provided in the (Additional file 1 and Additional file 2).

\section{$16 \mathrm{~S}$ rDNA standard solutions}

One Gram-positive $(B t)$ and two species of Gram-negative (Ss and $E c$ ) bacteria were streaked onto Luria-Bertani (LB; Difco, Detroit, MI, USA; 2\% [w/v] agar) plates and grown overnight at room temperature whereupon a single colony of each was selected. All these strains had previously been isolated from commercially available ground or whole chicken and identified based upon 16S $r$ RNA gene sequencing [1]. Each selected colony was mixed with $50 \mu \mathrm{L}$ PrepMan Ultra (Applied Biosystems, Foster City, CA, USA), heated $15 \mathrm{~min}$ at $99^{\circ} \mathrm{C}$ in a thermocycler (iCycler, BioRad, Hercules, CA, USA), cell debris was collected into a pellet by centrifugation (Eppendorf 5415R, Hamburg, Germany throughout), and the supernatant collected into a fresh tube. Amplification of the $16 \mathrm{~S} r \mathrm{RNA}$ gene was then performed as follows. Each PCR cocktail contained $25 \mu \mathrm{L}$ GoTaq Green 2× (Promega, Madison, WI, USA), $5 \mu \mathrm{L}$ $(10 \mu \mathrm{M})$ each of EubA and EubB [29] forward and reverse primers, $14 \mu \mathrm{L}$ PCR water (i.e., free of all DNA, RNase, and DNase; Qiagen Sciences, Germantown, MD, USA), and $1 \mu \mathrm{L}$ of the aforementioned genomic DNA template. Thermocycler conditions were as follows: DNA denaturation at $95^{\circ} \mathrm{C}$ for $90 \mathrm{~s}, 40$ total cycles consisting of denaturing at $95^{\circ} \mathrm{C}$ for $30 \mathrm{~s}$, annealing at $55^{\circ} \mathrm{C}$ for $45 \mathrm{~s}$, extension at $72^{\circ} \mathrm{C}$ for $60 \mathrm{~s}$ [25]; as a final extension, samples were maintained at $72^{\circ} \mathrm{C}$ for $5 \mathrm{~min}$.

Upon determining the presence of the 16S $r$ RNA gene using gel electrophoresis (ca. 1400 bp product), the PCR products were purified using AmPure magnetic beads (Agencourt Bioscience [Beckman Coulter Inc.], Beverly, MA, USA) as detailed previously [1]. The concentration of these various target DNA standards $\left([T]_{i}\right)$ was determined using a NanoDrop ND-1000 UV-VIS Spectrophotometer (NanoDrop Technologies Inc, Wilmington, DE, USA) where $2 \mu \mathrm{L}$ of undiluted, purified PCR product was placed onto the apparatus and the OD measured $(260 \mathrm{~nm}) . \mathrm{OD}_{260}$ values were converted to concentration (ng DNA $\mu \mathrm{L}^{-1}$ ) by comparing them with solutions of known DNA concentration $(\sim 67,50,38,28,21,16,12$, and $0 \mathrm{ng} \mu \mathrm{L}^{-1}$ of Lambda DNA HindIII digest, SigmaAldrich, St. Louis, USA). Dilutions were made on this original cleaned-up standard so that the final concentration of DNA was $\sim 10^{9} 16 \mathrm{~S} r \mathrm{DNA}$ copies per $\mu \mathrm{L}$ (i.e., this defines $[T]_{i=0}$ ). When used as a $q$ PCR standard set of solutions 5 additional 1:10 dilutions were made (i.e., $[T]_{i=1}$ to $\left.[T]_{i=5}\right)$.

\section{$q \mathrm{PCR}$}

Sheared salmon sperm DNA (Ambion, Austin, TX, USA) was used to suppress the apparent binding of standard or unknown target DNA to the walls of the mixing tubes (RNase/DNase/pyrogen-safe Denville Scientific, Posi-Click, $1.7 \mathrm{~mL}$ polypropylene micro-centrifuge tubes). The salmon sperm DNA was diluted so that the final concentration was $4 \mathrm{ng}$ per reaction. QuantiFast SYBR Green (Qiagen Sciences) was utilized where each polymerase chain reaction contained: $12.5 \mu \mathrm{L} 2 \times$ QuantiFast SYBR green, $2.5 \mu \mathrm{L}$ of a $10 \mu \mathrm{M}$ stock solution of each forward and reverse primers (all primers herein are reported $\left[5^{\prime} \rightarrow 3^{\prime}\right]$; Brochothrix: Forward [Broc PA] $=$ CAC AGC TGG GGA TAA CAT CGA, Reverse [Broc PB] = GGT CAG ACT TTC GTC CAT TGC C, 262 bp product; Shigella: Forward [Shig 2A] = TTA GCT CCG GAA GCC ACG, Reverse [Shig 2B] = ATA CTG GCA AGC TTG AGT CTC GT, 226 bp product), $6.5 \mu \mathrm{L}$ PCR $\mathrm{H}_{2} \mathrm{O}$ (containing the 4 ng sheared salmon sperm DNA as a blocking reagent), and $1 \mu \mathrm{L}$ template DNA (i.e., either $[T]_{i}$ or $[T]_{j}$; $i=0,1, \cdots, 6$ and $j=0,1,2,3)$. All experiments were run on an Applied Biosystems 7500 FAST (Carlsbad, CA, USA) real-time PCR and the conditions were programmed according to the QuantiFast SYBR green protocol (Qiagen Sciences) [25]. DNA melt-curve [30] data were always collected and checked to confirm that the appropriate PCR product was being amplified in unknown DNA extractions. For testing isolates (see below) other than the above, a set of "universal" $16 \mathrm{~S} r$ DNA primers was generated based upon minor modifications of oligonucleotides published by Nadkarni et al. [31]: Universal Forward (16S $\mathrm{FU})=$ GTG CCA GCA GCC GCG GTA ATA C, Universal Reverse $(16 S \mathrm{RU})=$ GAC TAC CAG GGT ATC TAA TCC, 291 bp product. The aforementioned Bt standard was used for all Gram-positive and the Ss standard was utilized for all Gram-negative species. Using either set of standards resulted in approximately the same values for $[T]_{j}$.

\section{qPCR data analysis}

Derivative-based methods have been shown [32] to have an advantage over the threshold cycle number $\left(C_{t}\right)$ method in calculating $q \mathrm{PCR}$ results given that they require no baseline correction. In our usage, $C_{\partial}$ is the calculated cycle $(C)$ number where $\partial^{2} R_{n} / \partial C^{2}=0$ (i.e., the maximum in $\partial R_{n} / \partial C$ ) which is based upon linear extrapolation from the two $\partial^{2} R_{n} / \partial C^{2}$ data points bounding 0 and constitute the last positive and first negative data points within the $\partial^{2} R_{n} / \partial C^{2}$ data. We have found (based on all the standards run herein) that there were only small differences between the $C_{\partial}$ and $C_{t}$ method from 
the standpoint of either $C_{\partial}$ or $C_{t}$ as a function of $\log _{10}$ $[T]_{i}$ slopes: Method $\mathbf{1}=\partial C_{\partial i} / \partial \log _{10}[T]_{i}=-3.34 \pm 0.0313$ $\left(\varepsilon_{\text {stnd }}=0.961 \pm 0.0125\right)$ and Method $2=\partial C_{t i} / \partial \log _{10}[T]_{i}=$ $-3.42 \pm 0.0214\left(\varepsilon_{\text {stnd }}=0.997 \pm 0.0126\right)$. We also found that there was a highly significant covariance statistic $\left(\sigma_{1.2}^{2} ; n=\right.$ 8 technical replicates $\times 3$ isolates $=24$ pairs of slopes) associated with the two methods alluded to above (e.g., $\rho_{1.2}=$ $\left.0.623\left[t_{\rho}=3.74, P=0.00114\right]\right)$ indicating that the two methods' slopes vary significantly together which is reasonable, and expected, for different calculation methods used on the same "raw" data $\left(R_{n}-v s-C\right)$. We prefer the $C_{\partial}$-based technique because it is better-defined and more objective than $C_{t}$-based values which use thresholds assigned by thermocycler software (or user-defined). Most importantly, however, we have observed consistently smaller standard deviations (the average $s$ across all observations was 0.304 for $C_{\partial i}$ and 0.522 for $C_{t i}$ ) using the derivative method. All target DNA concentrations reported in Tables are based upon the $[T]_{j}$ calculation provided in "Abbreviations, Symbols, \& Equations" above.

\section{Organisms used for extraction method testing Screening all extraction methods}

$B t, S s$ and $E c$ bacterial strains were streaked onto LB plates and incubated at $30^{\circ} \mathrm{C}$ until colonies were about $1 \mathrm{~mm}$ in size. Three separate colonies (clones) for each isolate were chosen and inoculated into 3 lots (one colony per lot) each of $\mathrm{LB}$ broth and grown at $30^{\circ} \mathrm{C}$ at $200 \mathrm{rpm}$ (i.e., $n=3$; a randomized complete block design) [27]. After $16 \mathrm{hrs,} \mathrm{each} \mathrm{isolate's} 3$ biological replicates were chilled in an ice-bath and $6 \times 6$ drop-plated [33] on solid LB media so that all DNA quantification could be eventually normalized to colony forming units (CFU). After plating, each overnight culture was broken up into numerous $1 \mathrm{~mL}$ aliquots, centrifuged at 13,000 rpm $(15,682 \times g)$, and supernatant discarded. These bacterial pellets were stored at $-20^{\circ} \mathrm{C}$ until needed for each set of extractions. Immediately before use, pellets were thawed and re-centrifuged to remove excess liquid and/or condensation.

\section{Quantitative performance of High Pure, Agencourt and Omnilyse DNA extraction protocols}

Various bacterial strains (Gram-positive: Staphylococcus aureus" [RN4220; source: bovine mastitis], Streptococcus pneumoniae [ground chicken], Enterococcus faecalis [whole chicken], Lactococcus lactis [salad bar lettuce], and Carnobacterium maltaromaticum [pork sausage]; Gram-negative: Salmonella Typhi* [G8430, CDC], Pseudomonas oleovorans [ground chicken], Aeromonas salmonicida [raw shrimp], Kluyvera ascorbata [salad bar lettuce], Pantoea agglomerans [salad bar lettuce], Rahnella aquatilis [salad bar lettuce \& tomato], Acinetobacter lwoffii [ground chicken], Hafnia alvei [salad bar lettuce], Citrobacter frenundii [ground chicken], Serratia proteamaculans [ground chicken]), were streaked onto LB plates and incubated at $30^{\circ} \mathrm{C}$ until colonies were about $1 \mathrm{~mm}$ in size. The preceding bacterial isolates marked with an asterisk were obtained from a local microbiological collection and 4 primer-based $16 \mathrm{~S} r \mathrm{DNA}$ sequencing [1] was used to substantiate their putative identity. All other isolates were obtained from a collection produced during a population (culturable) study from this group previously published [1]. As before, 3 colonies (i.e., $n=3$ biological replicates) were chosen for each isolate and inoculated into LB broth at $30^{\circ} \mathrm{C}$ at $200 \mathrm{rpm}$. One isolate, Pseudomonas oleovorans, was also grown in tryptic soy broth/plates (TSB) due to our concern that this organism did not seem to grow as well on LB. Numerous $1 \mathrm{~mL}$ samples from the overnight culture were selected and centrifuged at 13,000 rpm and the supernatant was discarded. These bacterial pellets were then stored at $-20^{\circ} \mathrm{C}$ until needed for the various extraction experiments. As previously mentioned, each of the isolates' three cultures were also drop-plate enumerated so that all DNA quantification could be normalized to $\mathrm{CFU}$.

\section{Extraction procedures and yields per $\mathrm{mL}$ of culture Fast ID kit (Genetic ID NA, Inc, Fairfield, IA)}

This genomic DNA extraction kit has been used [34] for isolating "high quality" DNA from eukaryotes such as higher plants. To each thawed bacterial pellet, $1 \mathrm{~mL}$ of Genomic Lysing buffer and $10 \mu \mathrm{L}$ of Proteinase K solution $\left(10 \mathrm{mg} \mathrm{mL}^{-1}\right)$ were added. Samples were transferred to $2 \mathrm{~mL}$ tubes for easier handling and incubated at $65^{\circ} \mathrm{C}$ for 30 minutes in a water bath (Thermo Scientific 280 Series). Samples were centrifuged at 10,000 rpm (i.e., $9,279 \times g$ ) for 5 minutes and $500 \mu \mathrm{L}$ of the supernatant was transferred to another sterile $2 \mathrm{~mL}$ tube to which $500 \mu \mathrm{L}$ of Genomic Bind buffer was added and mixed by pipetting. Another centrifugation at 10,000 rpm for $5 \mathrm{mi}-$ nutes followed and the supernatant was then pipetted into DNA columns (provided in kit). Columns were spun at 1,000 rpm (i.e., $93 \times g$ ) for 5 minutes and the flow-through was discarded. The column membrane was washed once with $800 \mu \mathrm{L}$ Genomic Wash Buffer and subsequently washed $3 \times$ with $800 \mu \mathrm{L}$ of $75 \% \mathrm{EtOH}$ making sure to discard the flow-through after each wash. After the last wash, the column was centrifuged briefly at high speed to completely dry the membrane. The column was then transferred to a sterile $1.7 \mathrm{~mL}$ centrifuge tube whereupon $100 \mu \mathrm{L}$ of $1 \times$ Tris-EDTA (TE) buffer was pipetted onto the membrane and left to incubate for $10 \mathrm{~min}$ at $65^{\circ} \mathrm{C}$ in a dry bath. The column was centrifuged $(10,000 \mathrm{rpm})$ for 30 seconds to collect the DNA. Assay volume for calculations $\sim 100 \mu \mathrm{L}$. 


\section{Near-boiling aqueous solutions}

Fifty $\mu \mathrm{L}$ of either RNA-free water (Qiagen Sciences Inc., Germantown, MD) or Prepman Ultra (Applied Biosystems, Foster City, CA) were added to thawed pellets. Samples were then placed in a dry bath at $99^{\circ} \mathrm{C}$ for 15 minutes, allowed to cool, and centrifuged for $3 \mathrm{~min}$ at $13,000 \mathrm{rpm}(15,682 \times g)$. The supernatant was transferred to a sterile $1.7 \mathrm{~mL}$ micro-centrifuge tube. Assay volume for calculations $\sim 50 \mu \mathrm{L}$.

Trizol max bacterial RNA isolation kit (Invitrogen, Carlsbad, CA) One $\mathrm{mL}$ of Trizol reagent was mixed with the thawed bacterial pellet and the sample was incubated at room temperature for 5 minutes at which point $200 \mu \mathrm{L}$ of chloroform was added. Tubes were vigorously mixed by manual shaking for 10-15 seconds and left at room temperature for $3 \mathrm{~min}$. Samples were centrifuged at $11,000 \times g(10,888 \mathrm{rpm})$ for 15 minutes at $6^{\circ} \mathrm{C}$, after which the clear upper phase was carefully removed and discarded. Three hundred $\mu \mathrm{L}$ of $\mathrm{EtOH}$ was then added and tubes were inverted several times to mix contents. After mixing, samples were kept at room temperature for $3 \mathrm{~min}$ then centrifuged $(2,000 \times g)$ for $5 \mathrm{~min}$ at $6^{\circ} \mathrm{C}$. The supernatant was carefully removed and pellets were washed with $1 \mathrm{~mL} 0.1 \mathrm{M}$ sodium citrate in $10 \% \mathrm{EtOH}$ followed by a 30 minute incubation at room temperature. Samples were again centrifuged $(2,000 \times g)$ for 5 minutes at $6^{\circ} \mathrm{C}$ and another wash with the sodium citrate solution, incubation, and centrifugation were repeated. After centrifugation, the supernatant was discarded and the pellets were left to air dry for approximately 45 minutes after which $300 \mu \mathrm{L}$ of an $8 \mathrm{mM} \mathrm{NaOH}$ solution was applied. Lastly, $10 \mu \mathrm{L}$ of $1 \mathrm{M}$ 4-(2-hydroxyethyl)-1-piperazineethanesulfonic acid (HEPES) buffer was added ( $\mathrm{pH} \sim 7$ ). Assay volume for calculations $\sim 300 \mu \mathrm{L}$.

\section{DNEasy blood \& tissue kit (Qiagen Sciences Inc, Germantown, MD)}

Two hundred $\mu \mathrm{L}$ of PBS was added to each pellet and $20 \mu \mathrm{L}$ Proteinase K (solution provided with kit; concentration not reported) were added along with $200 \mu \mathrm{L}$ Buffer $\mathrm{AL}$ and briefly vortexed. Samples were incubated at $56^{\circ} \mathrm{C}$ in a dry bath for 10 minutes and $200 \mu \mathrm{L}$ of $\mathrm{EtOH}$ was added and mixed. This suspension was transferred onto a filter column and centrifuged for $1 \mathrm{~min}$ at 8,000 rpm (i.e., $5,939 \times g)$. The collection tube was discarded and replaced, after which $500 \mu \mathrm{L}$ Buffer AW1 was added, centrifuged at $8,000 \mathrm{rpm}$ for $1 \mathrm{~min}$ and collection tube was again discarded. Five hundred $\mu \mathrm{L}$ of AW2 was added to the column and centrifuged for $3 \mathrm{~min}$ at 13,200 rpm (i.e., $16,168 \times g)$. The filter column was then placed into a clean $1.7 \mathrm{~mL}$ centrifuge tube and $200 \mu \mathrm{L}$ Buffer AE was pipetted onto the center of the membrane. The column was left to sit for 1 minute before centrifuging at 8,000 rpm for
1 minute at which point the DNA solution was collected. Assay volume for calculations $\sim 200 \mu \mathrm{L}$.

\section{"Labiase" enzyme (Sigma-Aldrich, St. Louis, MO)}

A $10 \mathrm{~mL}$ solution of labiase $\left(5 \mathrm{mg} \mathrm{mL}^{-1}\right)$ [14] was made and $300 \mu \mathrm{L}$ was then added to each bacterial cell pellet and mixed with the pipette. Samples were incubated at $37^{\circ} \mathrm{C}$ for 3 hours after which samples were subjected to dry bath at $99^{\circ} \mathrm{C}$ for 15 minutes and then spun down for $3 \mathrm{~min}$ at 13,200 rpm whereupon the supernatant was collected. Assay volume for calculations $~ 300 \mu \mathrm{L}$. These results have not been included in the tables due to extremely poor results (little change in $C_{\partial j}$ with each $j^{\text {th }}$ dilution).

\section{Genscript BacReady (GenScript Corporation, Piscataway, NJ)}

One hundred $\mu \mathrm{L}$ of Genscript reagent solution was added to each bacterial pellet. Samples were incubated at room temperature for 4 hours. Because the solutions were turbid after incubation, another $100 \mu \mathrm{L}$ reagent was added and gently mixed by pipette and incubated overnight at $4^{\circ} \mathrm{C}$. Assay volume for calculations $\sim 200 \mu \mathrm{L}$.

\section{Agencourt Genfind v2 (Beckman Coulter, Indianapolis, IN)}

A $100 \mathrm{mg} \mathrm{mL}^{-1}$ solution of both RNaseA and lysozyme were made but all other solutions used were provided. To each pellet, $400 \mu \mathrm{L}$ of lysis buffer, $9 \mu \mathrm{L}$ of a Proteinase $\mathrm{K}$ solution ( $96 \mathrm{mg} \mathrm{mL}^{-1}$ ), $1 \mu \mathrm{L}$ of a RNaseA solution, and $12 \mu \mathrm{L}$ of a lysozyme solution were added. Cells were lysed for 10 minutes at $37^{\circ} \mathrm{C}$ at which point $633 \mu \mathrm{L}$ of a binding buffer containing magnetic beads $(1.5 \times$ sample volume) was pipetted into the samples and left to incubate for 5 minutes at room temperature. The beads were collected on a Dynal MPC-S magnet for $15 \mathrm{~min}$ and the supernatant was discarded. The magnetic beads were washed with $1.6 \mathrm{~mL}$ of Wash Buffer 1 with gentle resuspension (pipette), collected again on the magnet, and the supernatant was discarded; repeat this wash step. Subsequently, $1 \mathrm{~mL}$ of Wash Buffer 2 was added; this was was performed $2 \times$. Once the second wash was completed, $500 \mu \mathrm{L}$ of pure water was added to the beads and re-suspended. A two minute incubation at room temperature followed, and beads were magnetically isolated for 5 minutes. The supernatant was then carefully transferred to a sterile $1.7 \mathrm{~mL}$ centrifuge tube. Assay volume for calculations $\sim 500 \mu \mathrm{L}$.

\section{QuickExtract bacterial DNA kit (Epicentre Biotechnologies, Madison, WI)}

To each bacterial pellet, $100 \mu \mathrm{L}$ of QuickExtract Bacterial DNA Extraction Solution and $1 \mu \mathrm{L}$ of lysozyme solution (Epicentre proprietary solution, concentration not provided by manufacturer) was added and tubes were inverted for mixing. Samples were incubated at room 
temperature for 2 hours. Since all the solutions had not clarified an additional incubation overnight at $4^{\circ} \mathrm{C}$ was performed. When these samples were tested most had poor $\varepsilon$ - $(0.9 \geq \varepsilon \geq 1.1)$ and/or $\rho_{x \cdot y}^{2}$-values (for $x=\log _{10} 0.1^{j}$ and $y=C_{\partial \mathrm{j}}$ ) as well as excessive variability between replicates (Figure 1, red symbols). However, when an AmPure DNA clean-up step was used on these samples, the results were far better and are reported herein (Figure 1, green symbols). This step involved adding $72 \mu \mathrm{L}$ of AmPure magnetic beads (Agencourt Bioscience, Beverly, MA, USA) to $40 \mu \mathrm{L}$ of the QuickExtract solution and mixing thoroughly using a pipette. Magnetic separation of the bead•DNA complex (SPRIplate 96-R magnetic plate) was performed for 5 min and the supernatant was discarded. While on the magnet, beads were washed with $150 \mu \mathrm{L}$ of $70 \% \mathrm{EtOH}$ for 30 seconds and the solution discarded. This wash was repeated and after discarding the supernatant, the beads were allowed to air-dry for 30-45 minutes at which point $40 \mu \mathrm{L}$ of PCR water was added to re-suspend the beads. The beads were separated magnetically for $5 \mathrm{~min}$ and $30 \mu \mathrm{L}$ of the solution was carefully removed. Assay volume for calculations $\sim 100 \mu \mathrm{L}$.

\section{High pure PCR template prep kit (Roche Diagnostics, Indianapolis, IN)}

Two hundred $\mu \mathrm{L}$ of PBS was added to the bacterial pellets and re-suspended whereupon $5 \mu \mathrm{L}$ of lysozyme $\left(10 \mathrm{mg} \mathrm{mL}^{-1}\right)$ was added and left to incubate at $37^{\circ} \mathrm{C}$ for

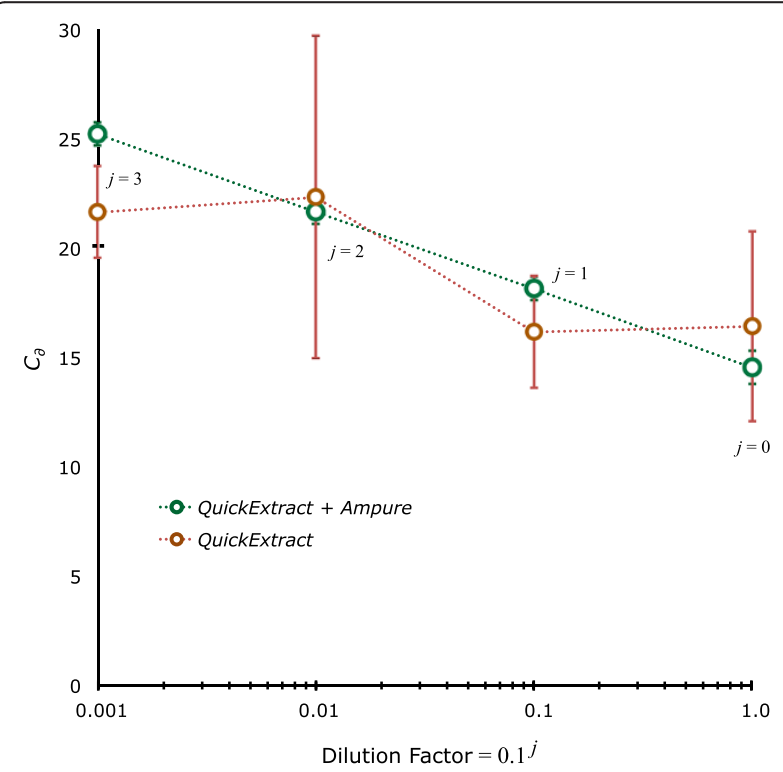

Figure 1 Semi-Log plot of $C_{\partial j}$ (QuickExtract \pm Ampure bead clean-up) as a function of dilution. Each data point is a mean of 3 replicates $\pm s$. These data demonstrate the poor performance of the QuickExtract protocol when used without subsequent DNA clean-up (Ampure beads).
15 minutes. After incubation, $200 \mu \mathrm{L}$ Binding buffer was added along with $40 \mu \mathrm{L}$ Proteinase $\mathrm{K}$ (included in kit) and followed with another incubation step at $70^{\circ} \mathrm{C}$ for 10 minutes. One hundred $\mu \mathrm{L}$ of isopropanol was added and sample was pipetted onto a filter column and spun at $8,000 \times g$ for 1 minute. Collection tubes were discarded, replaced and $500 \mu \mathrm{L}$ Inhibitor Removal buffer was added to the column and spun down at $8,000 \times g$ for 1 minute. The collection tube was again discarded, replaced, and $500 \mu \mathrm{L}$ of Wash buffer was added and spun down at the same rate. The wash was repeated a second time, making sure to discard the flow-through. The column was centrifuged an extra 15 seconds at high speed to ensure that the membrane was dry, then transferred to a new $1.7 \mathrm{~mL}$ centrifuge tube where $200 \mu \mathrm{L}$ of Elution buffer was pipetted onto the membrane and spun down at $8,000 \times g$ for 1 minute to collect DNA. Assay volume for calculations $\sim 200 \mu \mathrm{L}$.

\section{"BeadBug" microtube homogenizer (Benchmark Scientific Inc, Edison, NJ) combined with High Pure}

Each bacterial pellet was suspended in $1 \mathrm{~mL}$ of PBS and transferred to tubes containing BeadBug beads $(500 \mu \mathrm{m}$ diameter) especially made for the BeadBug homogenizer. Cells were then mixed with the beads for 2 minutes at $3,000 \mathrm{rpm}$ and tubes were spun down for $3 \mathrm{~min}$ at 13,200 rpm. The supernatant was carefully collected and dispersed into five sterile $1.7 \mathrm{~mL}$ centrifuge tubes, each containing $\sim 200 \mu \mathrm{L}$. The High Pure extraction was then followed as outlined above. The DNA solution from all 5 tubes, was then combined for future use. Assay volume for calculations $\sim 1000 \mu \mathrm{L}$.

\section{Omnilyse (Claremont BioSolutions, Upland, CA)}

The Omnilyse device [9] consists of a disposable $3 \mathrm{~mL}$ syringe and an attachment with a mixing chamber as well as inlet/outlet ports. A small motor equipped with a "precision-cut impellor" has been installed in the mixing chamber along with the zirconia/silica beads. Upon activation with the included battery, the motor drives the impellor at a rate $\geq 30,000 \mathrm{rpm}$ when the chamber is filled with both sample and beads thereby generating a high shear force between beads causing disruption of cells caught within this "shear flow". To each pellet, $500 \mu \mathrm{L}$ of PCR water was added and the cells were re-suspended. The Omnilyse syringe apparatus was assembled according to manufacturer directions and connected to the $6 \mathrm{~V} \mathrm{Bat-Pac}$ battery provided with the kit. Before use, each syringe and chamber containing the beads was washed with $500 \mu \mathrm{L}$ PCR-grade water, consisting of a total of 6 washes (counting both uptake and output) being performed in $\sim 1 \mathrm{~min}$. Once this pre-wash process was complete, the syringe was moved to the bacterial suspension and a small amount was drawn up 
before the battery was turned on. The remainder of the sample was then carefully run through the chamber a total of 18-20 times within a 2 minute time frame. Assay volume for calculations $\sim 500 \mu \mathrm{L}$.

\section{Results and discussion}

Experimental approach

In order to perform quantitative metagenomic analyses of native, Eubacterial populations, an efficient set of genomic DNA extraction protocols is desired. Towards this end we have tested a dozen "next generation" DNA extraction procedures recommended by molecular biologist colleagues, or sampled from recent literature, using a $q$ PCR assay which works for any "true" bacterial isolate in terms of obtaining target gene copy number per CFU. From prior experience [1] working with the 16S $r$ RNA gene extracted from various organisms, we know that stnd and unk DNA $q$ PCR efficiencies can differ substantially and make target DNA quantitation more error-prone than need be. To address this problem, we developed a $q \mathrm{PCR}$ protocol and simple algorithm [25] which took into account, and corrected, such $\varepsilon$-variation between samples of unknown DNA concentration and their associated standard solutions. In the current work, using this approach, we thrice-cultured various test organisms in a randomized complete block design [27], used a dropplate method [33] to estimate the total CFU mL $\mathrm{mL}^{-1}$ for each biological replicate (or block), numerous $1 \mathrm{~mL}$ subsamples from each of the three cultures per isolate $(12 \times$ Gram-negative, 6x Gram-positive) were selected, solids (i.e., cells) were centrifuged out, and the pellets were frozen $\left(-20^{\circ} \mathrm{C}\right)$ to preserve them for eventual testing as well as assist in breaking, or softening, the cell envelopes [18] with a concomitant diminishment of cell viability [35]. These frozen concentrates of cells were then used for testing commercially available protocols, discussed below. For many of our test organisms, the number of copies of the 16S $r$ RNA gene per genome (typically 5-8) is known [36] or can be surmised from knowledge about genetically related types: e.g., using Listeria spp. for Bt $[37,38]$. Also, normalization of all gene copy number results to CFUs provides us with a relative measure of the closeness to truly quantitative extraction of genomic DNA.

\section{Survey of 12 bacterial cell lysis and extraction protocols} with $B t$, Ss, and $E c$

DNA extraction results from gram-positive organisms

Table 1 displays $\delta$-normalized 16S $r$ DNA copy number data (Broc PA/PB primer set) for all extraction protocols performed on 3 biological replicates (blocks) of Bt. The reported means have been sorted from lowest to highest and those with a different letter are taken to be "significantly" different at the $P=0.05$ level. For these Bt extractions alone, the $S E(\sqrt{E M S \div n}=24.4)$ [28] was sizable because of the large variation $(0.322 \pm 0.0497$ to $934 \pm$ $19.916 \mathrm{~S} r \mathrm{DNA}$ copies $\mathrm{CFU}^{-1}$ ) in the quantity of genomic DNA being extracted from this Gram-positive organism and is testimony to the difficulty in efficiently disrupting such murein-laden cell walls. The $H S D$ multiple range test is also quite rigorous (e.g., no significant difference between $0.322 \pm 0.0497$ [FastID] and 22.0 \pm 3.57 [BeadBug]

Table 1 Colony forming unit-normalized 16S rDNA copy number for various extraction protocols associated with three biological replicates of Brochothrix thermosphacta

\begin{tabular}{|c|c|c|c|c|c|c|}
\hline \multirow[b]{2}{*}{ Extraction methods } & \multicolumn{5}{|c|}{ Brochothrix copies $16 \mathrm{~S}$ rRNA "gene" per CFU } & \\
\hline & Culture 1 & Culture 2 & Culture 3 & Mean & Stdev & \\
\hline Fast ID & 0.265 & 0.353 & 0.349 & 0.322 & 0.0497 & $a$ \\
\hline Boiling Water & 0.222 & 1.05 & 0.693 & 0.655 & 0.415 & $a$ \\
\hline Trizol & 0.484 & 1.74 & 0.643 & 0.956 & 0.684 & $a$ \\
\hline DNEasy & 0.602 & 1.72 & 1.28 & 1.20 & 0.561 & $a$ \\
\hline PrepMan & 0.916 & 2.67 & 2.04 & 1.88 & 0.889 & $a$ \\
\hline Genscript & 8.67 & 10.9 & 8.72 & 9.43 & 1.27 & $a$ \\
\hline BeadBug & 18.7 & 21.6 & 25.8 & 22.0 & 3.57 & $a b$ \\
\hline Agencourt & 143 & 189 & 91.4 & 141 & 48.8 & $b c$ \\
\hline QuikExtract (Ampure) & 329 & 73.6 & 248 & 217 & 131 & c \\
\hline High Pure & 596 & 544 & 579 & 573 & 26.9 & $d$ \\
\hline \multirow[t]{4}{*}{ Omnilyse } & 918 & 956 & 927 & 934 & 19.9 & $e$ \\
\hline & & $\mathrm{CFU} \mathrm{mL} \mathrm{m}^{-1}$ & & & & \\
\hline & $8.62 \times 10^{6}$ & $6.92 \times 10^{6}$ & $7.92 \times 10^{6}$ & & & \\
\hline & $\pm 5.66 \%$ & $\pm 4.46 \%$ & $\pm 7.44 \%$ & & & \\
\hline
\end{tabular}

Any two means reported with different letters are significantly different at the $P=5 \times 10^{-2}$ level. 
16S $r$ DNA copies $\mathrm{CFU}^{-1}$ ) due to the relatively large $q_{P}$ value which, in turn, is due to the sizeable number of comparisons $(m=11$; the labiase treatment was not included due to poor $q \mathrm{PCR}$ behavior). Of these eleven DNA extraction methods, 7 were statistically not much better than the extraction of DNA with hot $\left(99^{\circ} \mathrm{C}\right)$ RNA-free water $\left(0.655 \pm 0.415\right.$ copies $\left.\mathrm{CFU}^{-1}\right)$. From our experience such a low efficacy in DNA extraction is more expected than not inasmuch as DNA extraction biases, which result in low $[T]_{j=0}$, can be caused by many problems such as chromosomal shearing and, if pure DNA is required (as when we generate standard concentrations of $16 \mathrm{~S} r \mathrm{DNA}$ ), loses can occur associated with purification schemes such as AmPure magnetic beads (was not obvious in our usage, however: Figure 1). However, the observed large CFUnormalized gene copy number seen using the Agencourt procedure $\left(141 \pm 48.8\right.$ copies $\left.\mathrm{CFU}^{-1}\right)$ was not particularly surprising because $B t$ is known to form long (10-20 cells $\mathrm{CFU}^{-1}$ ), linear chains of rod-shaped cells [38].

However, the very high copy numbers observed using either the High Pure $\left(573 \pm 26.9\right.$ copies $\left.\mathrm{CFU}^{-1}\right)$ or Omnilyse $\left(934 \pm 19.9\right.$ copies $\left.\mathrm{CFU}^{-1}\right)$ techniques were unexpected. If $B t$ is similar to its nearest relative (Listeria spp.), there should be $6 \times 16 \mathrm{~S} r$ RNA gene copies per genome [36]. Thus, the Omnilyse result implies 934 copies $\mathrm{CFU}^{-1} \div 6$ copies genome ${ }^{-1} \sim 150$ genomes $\mathrm{CFU}^{-1}$ which suggests a substantially larger number of cells $\mathrm{CFU}^{-1}$ than noted above. For some organisms this relatively large 16S $r$ RNA gene copy number could be somewhat over-estimated since CFU count on solid media is typically underestimated. For instance, we have found that the ratio of MPN (liquid media-based) to CFU counting methods (pure cultures) for Campylobacter spp. $=2.58 \pm$ 0.909 [5]. However, CFU mortality on solid media is problematic for organisms with only $\sim 1$ or 2 cells $\mathrm{CFU}^{-1}$. To achieve a $100 \%$ extraction efficiency (EE; see Definitions Section, above) with an observation of 934 copies of the 16S $r$ RNA gene $\mathrm{CFU}^{-1}$ one could reasonably assume: 6 copies genome ${ }^{-1},>100$ cells $\mathrm{CFU}^{-1}$, no "correction" for growth losses on solid media because of the large CFU size, and 1-2, or more [39], genomes per cell since, during log-phase, some chromosomes can have several "replication bubbles".

To determine if $B t$ can have more than 100 cells $\mathrm{CFU}^{-1}$, we developed an optical measure of CFU size based upon the principle that turbidity of a relatively dilute solution (e.g., $\mathrm{OD} \leq 1)$ of suspended particles is proportional to the number of particles per volume $\times$ the projected area per particle. Thus, the turbidity, as measured by the optical density at $\sim 600 \mathrm{~nm}(\mathrm{OD})$, for bacterial cells of similar size and shape, is directly proportional to something related to number of particles \& size of those particles. By normalizing the OD of cell cultures to their cell density $(\delta)$ one factors out the particles per volume term.
Upon calculating the ratio $(\mathrm{OD} / \delta)_{B t} \div(\mathrm{OD} / \delta)_{S s}$ one achieves a measure of the number of $B t$ cells $\mathrm{CFU}^{-1}$ relative to the $S s$ standard's presumed number of cells $\mathrm{CFU}^{-1}$ (between 1 and 2 cells $\mathrm{CFU}^{-1}$ ). One such set of data are shown in Figure $2 \mathrm{~b}(\mathrm{OD} \leq 0.5)$ and indicate that $B t$ can have $\sim 100$ cells $\mathrm{CFU}^{-1}$. Replicating this experiment 6 times more we observed an average $(\mathrm{OD} / \delta)_{B t} \div(\mathrm{OD} / \delta)_{S s}=$ $128 \pm 66.1$ (ranging from 76.6 to $269, n=7$ ) for gently mixed cultures (using a $5 \mathrm{~mL}$ pipette). Performing the same analyses, but vortexing for $30 \mathrm{sec}$ prior to making dilutions, we observed average $(\mathrm{OD} / \delta)_{B t} \div(\mathrm{OD} / \delta)_{S s}=85.7 \pm$ 59.9 (ranging from 39.5 to $208, n=7$ ) whereupon these two mixing treatments were significantly different at the $P=0.0168$ level (“=FDIST $\left(F, m-1=1, \quad(m-1)^{* *}(n-1)=6\right)$ "; Log-transformed data). In a different set of comparable experiments, a similar result was obtained by diluting colonies of each organism ( $B t$ and $S s$ ) in LB broth until an OD of 1 was achieved at which point, upon vortexing, they were $6 \times 6$ drop-plated plated, grown overnight, and enumerated. Under these conditions we found that the ratio of $S s$ colony counts to $B t$ counts (both for an $\mathrm{OD} \sim 1$ ) was $151 \pm 47.1(n=7)$. We contend that the extreme difference (2-log $\delta$-separation between $B t$ and $S s$ OD data) in observed $\delta$ between these two rod-shaped, and similar-sized, organisms at the same OD (Figure 2a) and can only be related to differences in CFU dimension. All these results support the concept that $B t$ can have a large number of cells per CFU relative to $S s$ and that the Omnilyse technique of cell lysis provided close-to-quantitative genomic DNA extraction from this tough-walled [9], Grampositive organism. To achieve a complete agreement of the CFU-normalized OD results (average of the three above means $=\bar{x} \pm s_{\bar{x}}=121 \pm 12.5$ ) with the CFUnormalized 16S $r$ DNA copy data (i.e., $934 \pm 19.9$ copies $\mathrm{CFU}^{-1}$ ) we merely had to assume a bulk average of 1.28 genomes per cell [39] $\times 6$ gene copies per genome $\times 121$ cells $\mathrm{CFU}^{-1}$.

\section{DNA extraction results from gram-negative organisms}

Tables 2 and 3 display CFU-normalized 16S $r$ RNA gene copy number data (Shig $2 \mathrm{~A} / 2 \mathrm{~B}$ primer set) for all extraction protocols $(m=11)$ using $S s$ and $E c$ as target organisms. As with the $B t$ extractions (Table 1), these results demonstrated that the Omnilyse $\left(15.1 \pm 3.35\right.$ copies $\mathrm{CFU}^{-1}$ for $S s ; 26.9 \pm 3.39$ copies $\mathrm{CFU}^{-1}$ for $E c$ ), Agencourt (20.8 \pm 2.68 copies $\mathrm{CFU}^{-1}$ for $S s ; 16.0 \pm 5.35$ copies $\mathrm{CFU}^{-1}$ for $E c$ ) and High Pure $\left(8.33 \pm 1.21\right.$ copies $\mathrm{CFU}^{-1}$ for $S s ; 26.0 \pm 1.31$ copies $\mathrm{CFU}^{-1}$ for $E c$ ) genomic DNA extraction procedures were consistently the most efficient. It is interesting to note, however, that the High Pure + BeadBug combined Ss extraction treatment displayed $2.07 \pm 0.0451$ copies $\mathrm{CFU}^{-1}$ which is $\sim 25 \%$ of the High Pure alone. Something similar was also observed for Ec's High Pure + BeadBug treatment (7.31 \pm 0.429 copies $\mathrm{CFU}^{-1}$ or $\sim 28 \%$ of the High Pure 

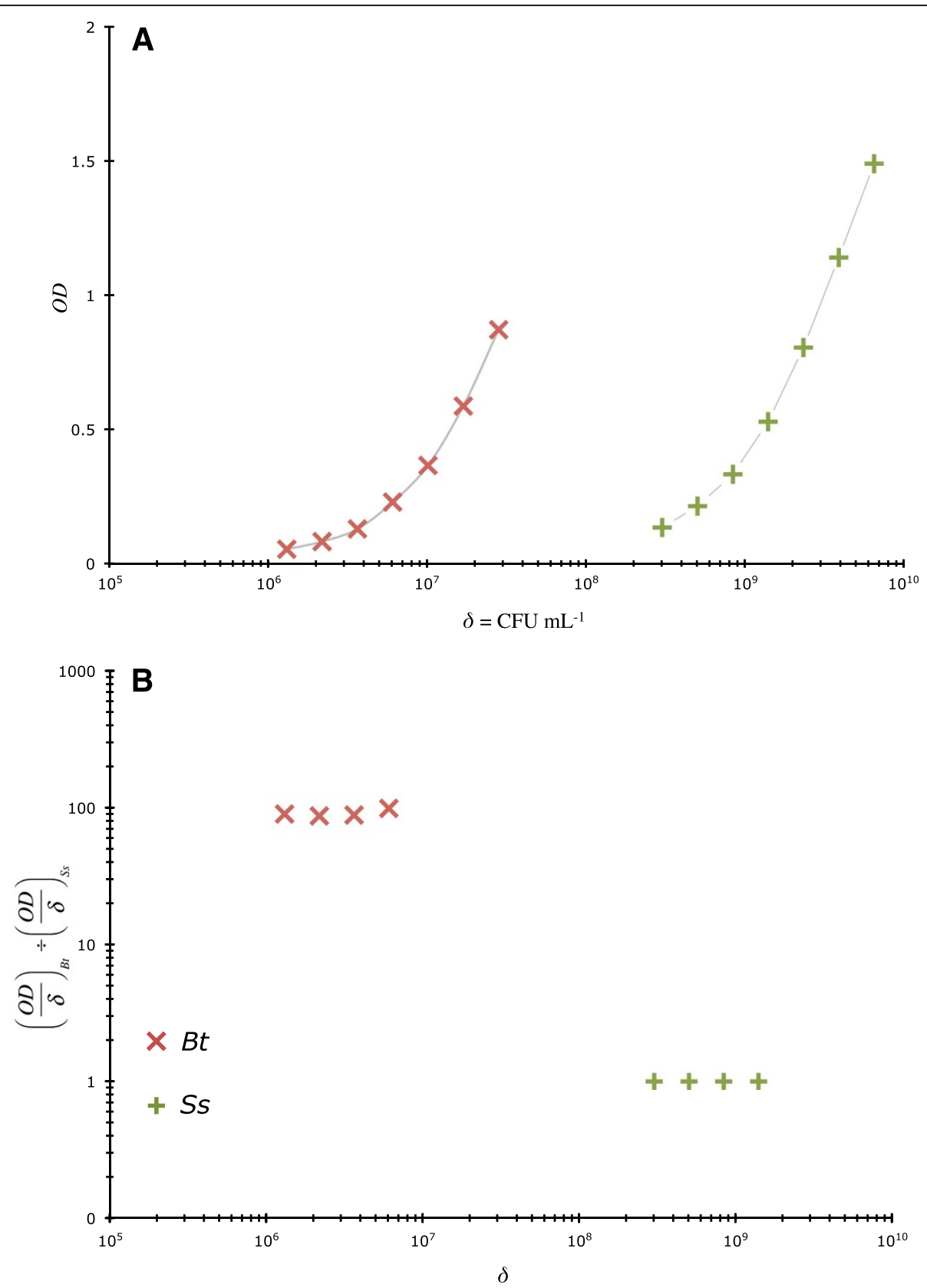

Figure 2 Estimation of the relative size of colony forming units. A) Semi-Log plot of optical density at $600 \mathrm{~nm}$ as a function of bacterial $(\times=B t ;+=S s)$ concentration $\left(\delta=C F U \mathrm{~mL}^{-1}\right)$. We have used the semi-Log format in this figure only in order to show all data on the same scale. All results are linear (for OD $\leq 0.5, \rho_{x \cdot y}^{2}=0.999\left[t_{\rho}=54.7, P=1.35 \times 10^{-5}\right]$ and $0.997\left[t_{P}=25.8, P=1.28 \times 10^{-4}\right]$ for $B t$ and $S$, respectively) on a non-Log scale. B) The ratio of Bt $\delta$-normalized OD ( 0.5 or less) at $600 \mathrm{~nm}$ to this same variable associated with $S$ s plotted with $\delta$.

alone). These possible evidences of excessive genomic DNA shearing were exacerbated when the BeadBug-based protocol was used on $B t$ (Table 1: $22.0 \pm 3.57{\text { copies } C F U^{-1}}^{-1}$ or only $\sim 4 \%$ of the High Pure alone). The Trizol (9.44 \pm 0.748 copies $\mathrm{CFU}^{-1}$ for Ss) and Fast ID (16.7 \pm 3.61 copies $\mathrm{CFU}^{-1}$ for $E c$ ) methods were relatively effective but for only one each of the 3 tested organisms. It is also curious that the QuickExtract (with AmPure DNA clean-up) procedure for the Gram-negative organisms was one of the worst $\left(1.23 \pm 0.399\right.$ copies $\mathrm{CFU}^{-1}$ for $S s ; 3.62 \pm 2.46$ copies $\mathrm{CFU}^{-1}$ for $E c$ ) but fairly efficient, albeit variable, for our Gram-positive test organism (Table 1: $217 \pm 131$ copies $\mathrm{CFU}^{-1} ; 289 \pm 57.3$ with culture \#2 removed). Of course, without the AmPure purification procedure, the QuickExtract $q \mathrm{PCR}$ behavior from all three isolates was extremely poor: e.g., $0.8>\varepsilon_{\text {unk }}>1.2$, $\varepsilon_{\text {unk }}$ highly variable, and, 
Table 2 Colony forming unit-normalized 16S rDNA copy number for various extraction protocols associated with three biological replicates of Shigella sonnei

\begin{tabular}{|c|c|c|c|c|c|c|}
\hline \multirow[b]{2}{*}{ Extraction methods } & \multicolumn{5}{|c|}{ Shigella copies $16 \mathrm{~S}$ rRNA "gene" per CFU } & \\
\hline & Culture 1 & Culture 2 & Culture 3 & Mean & $\overline{\text { Stdev }}$ & \\
\hline Quick Extract (AmPure) & 1.29 & 0.808 & 1.60 & 1.23 & 0.399 & $a$ \\
\hline Fast ID & 1.26 & 1.06 & 1.82 & 1.38 & 0.394 & $a$ \\
\hline BeadBug & 2.03 & 2.12 & 2.07 & 2.07 & 0.0451 & $a$ \\
\hline PrepMan Ultra & 2.62 & 2.30 & 3.99 & 2.97 & 0.898 & $a b$ \\
\hline DNeasy & 2.42 & 2.96 & 3.63 & 3.00 & 0.606 & $a b$ \\
\hline Boiling Water & 4.70 & 2.21 & 3.49 & 3.47 & 1.25 & $a b$ \\
\hline Genscript & 2.22 & 2.88 & 9.88 & 4.99 & 4.24 & $a b c$ \\
\hline High Pure & 6.96 & 8.74 & 9.28 & 8.33 & 1.21 & $b c$ \\
\hline Trizol & 9.03 & 8.98 & 10.3 & 9.44 & 0.748 & $c d$ \\
\hline Omnilyse & 18.7 & 14.4 & 12.1 & 15.1 & 3.35 & de \\
\hline \multirow[t]{4}{*}{ Agencourt } & 18.4 & 23.7 & 20.4 & 20.8 & 2.68 & $e$ \\
\hline & & $\mathrm{CFU} \mathrm{mL}^{-1}$ & & & & \\
\hline & $3.87 \times 10^{8}$ & $3.67 \times 10^{8}$ & $4.18 \times 10^{8}$ & & & \\
\hline & $\pm 16.7 \%$ & $\pm 5.35 \%$ & $\pm 0.940 \%$ & & & \\
\hline
\end{tabular}

Any two means reported with different letters are significantly different at the $P=5 \times 10^{-2}$ level.

for $B t, C_{\partial j}$ was not very linear with respect to $\log _{10}\left[0.1^{j}\right]$ (Figure 1, red symbols). We believe such poor $q \mathrm{PCR}$ results are an indicator of enzyme perturbation [26] by inhibitory substances in the extract because they were completely reversed upon AmPure clean-up whereupon $0.913<\varepsilon_{\text {unk }}<1.03$ as previously demonstrated in Figure 1 (green symbols). In order to observe an $100 \% E E$ associated with the 20.8 Ss 16S rDNA copies CFU ${ }^{-1}$ (Agencourt) observation, one could judiciously propose: 7 copies genome $^{-1}$ [36], 1.5 genomes cell $^{-1}$ [39], 1.5 cells $\mathrm{CFU}^{-1}$ and a 1.32 correction for growth losses on solid media (76\% plating efficiency). Similarly, for an $100 \% E E$ associated with an average of 26.9 Ec $16 \mathrm{~S}$ rDNA copies $\mathrm{CFU}^{-1}$ (Omnilyse) necessitates assuming: 7 copies genome ${ }^{-1}, 1.5$ genomes cell $^{-1}, 1.5$ cells $\mathrm{CFU}^{-1}$ and a 1.7 correction (59\% plating efficiency) for growth losses on solid media. These plating

Table 3 Colony forming unit-normalized 16S rDNA copy number for various extraction protocols associated with three biological replicates of Escherichia coli 079

\begin{tabular}{|c|c|c|c|c|c|c|}
\hline \multirow[b]{2}{*}{ Extraction methods } & \multicolumn{5}{|c|}{ E. coli copies $16 \mathrm{~S}$ rRNA "gene" per CFU } & \\
\hline & Culture 1 & Culture 2 & Culture 3 & Mean & Stdev & \\
\hline DNEasy & 2.98 & 2.55 & 4.62 & 3.38 & 1.09 & $a$ \\
\hline QuikExtrax (AmPure) & 2.07 & 2.34 & 6.46 & 3.62 & 2.46 & $a$ \\
\hline BeadBug & 7.43 & 6.83 & 7.66 & 7.31 & 0.429 & $a b$ \\
\hline Trizol & 7.07 & 13.9 & 3.77 & 8.25 & 5.17 & $a b c$ \\
\hline Boiling Water & 11.2 & 10.0 & 7.35 & 9.52 & 1.97 & $a b c$ \\
\hline PrepMan Ultra & 10.7 & 14.2 & 10.5 & 11.8 & 2.08 & $a b c$ \\
\hline Genscript & 12.7 & 12.0 & 18.9 & 14.5 & 3.80 & $b c$ \\
\hline Agencourt & 11.5 & 14.5 & 21.9 & 16.0 & 5.35 & $b c$ \\
\hline Fast ID & 12.5 & 18.6 & 18.9 & 16.7 & 3.61 & $c$ \\
\hline High Pure & 25.6 & 25.0 & 27.5 & 26.0 & 1.31 & $d$ \\
\hline \multirow[t]{4}{*}{ Omnilyse } & 28.6 & 23.0 & 29.1 & 26.9 & 3.39 & $d$ \\
\hline & & $\mathrm{CFU} \mathrm{mL}^{-1}$ & & & & \\
\hline & $5.61 \times 10^{8}$ & $6.04 \times 10^{8}$ & $6.13 \times 10^{8}$ & & & \\
\hline & $\pm 8.60 \%$ & $\pm 27.8 \%$ & $\pm 12.4 \%$ & & & \\
\hline
\end{tabular}

Any two means reported with different letters are significantly different at the $P=5 \times 10^{-2}$ level. 
efficiency correction terms seem unreasonably high (low efficiency) so it is probable that the number of genomes cell $^{-1}$ should be made higher (between 1.5 and 3). Backing up the larger genomes cell ${ }^{-1}$ value is the fact that actively dividing bacteria can contain 2 or more copies of complete, or partially-replicated, chromosomes per cell [39]. Of course, the greatest unknown variables in these calculations is plating efficiency-related correction factor for CFU losses on solid media and the number of genomes per cell. Since the above $E E$ calculations seem reasonable and, in fact, vary toward the high end, it is probable that the consistently best extraction procedures (Omnilyse, Agencourt and/or High Pure) are very efficient relative to standard genomic DNA protocols (PrepMan Ultra and DNEasy).

Because the CFU-normalized DNA yields for $B t$ were often more than 50 -fold greater than the equivalent for either $S s$ or $E c$, normal analysis of covariance is unreasonable. Alternatively, however, when the extraction methods for $B t$ were assigned a numerical value from $1=$ Fast $I D$ to 11 = Omnilyse (Table 1 extraction method order: 1, 2, , , 11 ) and used with either $S s^{\prime}$ s (Table 2 extraction methods top to bottom: 9, 1, 7, 5, 4, 2, 6, 10, 3, 11, 8) or Ec's (Table 3 extraction methods top to bottom: $4,9,7,3,2,5,6,8,1$, $10,11)$ CFU-normalized DNA yields, one can test the level of correlation between these organisms' DNA yield covariation with the $B t$-based method's order. Neither Ss- $\quad\left(\rho_{B t . S s}=0.464 \quad\left[t_{\rho}=1.66, \quad P=0.128\right]\right) \quad$ nor $E c$-based $16 \mathrm{~S} r \mathrm{DNA}$ yields $\left(\rho_{B t . S s}=0.462\left[t_{\rho}=1.65, P=0.131\right]\right)$ associated with the $B t$-based numerical treatments gave a "significant" correlation. A similar correlation can be made with the Ss-based method order (Table 2) and correlated with $E c$ DNA yields $\left(\rho_{S s . E c}=0.520\left[t_{\rho}=1.93, P=8.29 \times\right.\right.$ $\left.10^{-2}\right]$ ) indicating that there is a greater correlation, but still not statistically significant, between these two Gram-negative species from the standpoint of DNA yields. In other words, the various extraction protocols do not correlate well between species in terms of total genomic DNA yield.

\section{Survey of High Pure, Agencourt, and Omnilyse genomic DNA extraction methods used with other foodborne Eubacteria (5 Gram-positive, $10 \mathrm{Gram}$-negative) DNA extraction results from additional gram-positive organisms}

Table 4 displays $\delta$-normalized $16 \mathrm{~S} r \mathrm{DNA}$ copy number data (16S FU/16S RU primer set) for the 3 consistently most efficient extraction protocols (High Pure, Agencourt, and Omnilyse) from Tables 1-3 using various Gram-positive Eubacteria as target organisms. For 3 of the tested organisms, the Omnilyse device/process gave significantly greater yields of $16 \mathrm{~S} r \mathrm{DNA}$ : $C$. maltaromaticum lysis resulted in $7.03 \pm 0.746$ copies $\mathrm{CFU}^{-1}$ which was nearly 6-fold greater than either High Pure or Agencourt; E. faecalis provided $10.9 \pm 1.26$ copies $\mathrm{CFU}^{-1}$ which was more than 3-fold greater than the other two methods; lastly, we obtained $42.6 \pm 11.6$ copies $\mathrm{CFU}^{-1}$ from $S$. aureus which was 87-fold greater than either High Pure or Agencourt. Of the remaining 2 test isolates, Omnilyse was statistically equivalent to the other two extraction methods. The isolates $L$. lactis and $S$. aureus have been reported to have 5-6 copies per genome of $16 \mathrm{~S} r \mathrm{DNA}$ [36]. Therefore, assuming 6 copies per genome, 1 genome per cell, and $100 \%$ extraction efficiency the $L$. lactis and $S$. aureus results argue for 1 and 7 cells $\mathrm{CFU}^{-1}$, respectively. The relatively high number for $S$. aureus is probably reasonable since it has at least several cells $\mathrm{CFU}^{-1}$ which, under a microscope, can appear as "grape-like" clusters. (All the isolates discussed herein had been thoroughly vortexed before plating and therefore the relative number of cells $\mathrm{CFU}^{-1}$ could be smaller than those shown in photomicrographs.) All the other Gram-positive isolates in Table 4 have an unknown number of copies of $16 \mathrm{~S} r \mathrm{DNA} \mathrm{CFU}^{-1}$ but since these are likely to be $\leq 6$, we could argue that the Omnilyse procedure is nearly quantitative for these isolates as well.

\section{DNA extraction results from additional gram-negative organisms}

Tables 5 and 6 exhibit CFU-normalized 16S rRNA gene copy number data (16S FU/16S RU primer set) for the 3 reliably best extraction protocols from Tables 1-3 using various Gram-negative Eubacteria as target organisms. Table 5 provides information on the efficiency of genomic DNA extraction from Aeromonas salmonicida, Acinetobacter lwoffii, Citrobacter freundii, Hafnia alvei, and Kluyvera ascorbata. Using these 5 organisms, Omnilyse was the clear statistical winner especially with respect to A. lwoffii $(101 \pm 30.3$ [or $83.7 \pm 3.54$ if culture \#2 is removed] copies $\mathrm{CFU}^{-1}$ which is more than 20-fold greater than either High Pure or Agencourt) and C. freundii (20.8 \pm 3.96 copies $\mathrm{CFU}^{-1}$, more than 75-fold greater than the other techniques). Genomic DNA extracted from both $K$. ascorbata $\left(13.2 \pm 2.55\right.$ copies $\left.\mathrm{CFU}^{-1}\right)$ and $H$. alvei $\left(9.75 \pm 2.68\right.$ copies $\left.\mathrm{CFU}^{-1}\right)$ were also statistically better (on average $>2$-fold) using the Omnilyse method. A. salmonicida showed a statistically equivalent extractability of all 3 test methods (ranging from 11.1 \pm 0.115 to $17.2 \pm 4.09$ copies $\mathrm{CFU}^{-1}$ ). Of the 5 organisms in Table 5, we only know the number of $16 \mathrm{~S} r \mathrm{DNA}$ copies (6-7) per genome for $A$. lwoffii which therefore implies at least an average of 12 cells $\mathrm{CFU}^{-1}$. An internet search for this organism does provide some photomicrographs; one example showed the number of cells $\mathrm{CFU}^{-1}$ ranging from 1 or 2 to over $40: \bar{x} \pm s=18.5 \pm 14.4 \quad(n=12$, randomly chosen from a pool of 26); however, some of the cell clustering in photomicrographs is probably due to artifacts associated with sample preparation. Table 6 provides data on the relative efficiency of genomic DNA extraction from 
Table 4 Colony forming unit-normalized 16S rDNA copy number for the best extraction protocols (Tables 1, 2 and 3 ) associated with three biological replicates of various Gram-positive Eubacteria

\begin{tabular}{|c|c|c|c|c|c|c|c|}
\hline \multirow[b]{2}{*}{ Gram Pos isolates } & \multirow[b]{2}{*}{ Extraction method } & \multicolumn{5}{|c|}{ Copies 16S rRNA “gene" per CFU } & \\
\hline & & Culture 1 & Culture 2 & Culture 3 & Mean & $\overline{\text { Stdev }}$ & \\
\hline \multirow[t]{6}{*}{ Carnobacterium maltaromaticum } & High Pure & 0.711 & 0.679 & 1.34 & 0.909 & 0.374 & $\bar{a}$ \\
\hline & Agencourt & 1.56 & 1.24 & 2.07 & 1.62 & 0.419 & $a$ \\
\hline & Omnilyse & 6.20 & 7.65 & 7.23 & 7.03 & 0.746 & $b$ \\
\hline & & & $\mathrm{CFU} \mathrm{mL}^{-1}$ & & & & \\
\hline & & $5.63 \times 10^{8}$ & $5.34 \times 10^{8}$ & $3.89 \times 10^{8}$ & & & \\
\hline & & $\pm 11.1 \%$ & $\pm 22.5 \%$ & $\pm 37.6 \%$ & & & \\
\hline \multirow[t]{6}{*}{ Enterococcus faecalis } & High Pure & 3.05 & 2.14 & 2.76 & 2.65 & 0.465 & $a$ \\
\hline & Agencourt & 3.28 & 3.75 & 4.12 & 3.72 & 0.421 & $a$ \\
\hline & OmniLyse & 10.5 & 9.88 & 12.3 & 10.9 & 1.26 & $b$ \\
\hline & & & $\mathrm{CFU} \mathrm{mL} \mathrm{m}^{-1}$ & & & & \\
\hline & & $7.01 \times 10^{8}$ & $6.32 \times 10^{8}$ & $5.90 \times 10^{8}$ & & & \\
\hline & & $\pm 0.240 \%$ & $\pm 7.72 \%$ & $\pm 1.71 \%$ & & & \\
\hline \multirow[t]{6}{*}{ Lactococcus /catis } & High Pure & 4.19 & 3.11 & 2.74 & 3.35 & 0.753 & $a b$ \\
\hline & Agencourt & 1.15 & 1.48 & 1.44 & 1.36 & 0.180 & $a$ \\
\hline & Omnilyse & 4.58 & 8.28 & 5.47 & 6.11 & 1.93 & $b$ \\
\hline & & & CFU $\mathrm{mL}^{-1}$ & & & & \\
\hline & & $7.58 \times 10^{8}$ & $7.55 \times 10^{8}$ & $8.01 \times 10^{8}$ & & & \\
\hline & & $\pm 9.55 \%$ & $\pm 12.5 \%$ & $\pm 9.99 \%$ & & & \\
\hline \multirow[t]{6}{*}{ Staphylococcus aureus } & High Pure & 0.307 & 0.328 & 0.349 & 0.328 & 0.0210 & $a$ \\
\hline & Agencourt & 0.568 & 0.707 & 0.649 & 0.641 & 0.0698 & $a$ \\
\hline & OmniLyse & 30.3 & 44.2 & 53.3 & 42.6 & 11.6 & $b$ \\
\hline & & & $\mathrm{CFU} \mathrm{mL}^{-1}$ & & & & \\
\hline & & $5.54 \times 10^{8}$ & $4.58 \times 10^{8}$ & $4.96 \times 10^{8}$ & & & \\
\hline & & $\pm 7.44 \%$ & $\pm 1.66 \%$ & $\pm 14.8 \%$ & & & \\
\hline \multirow[t]{6}{*}{ Streptococcus pneumoniae } & High Pure & 9.95 & 8.55 & 7.14 & 8.55 & 1.41 & $a$ \\
\hline & Agencourt & 8.77 & 9.39 & 8.62 & 8.93 & 0.408 & $a$ \\
\hline & OmniLyse & 7.90 & 7.42 & 6.15 & 7.16 & 0.904 & $a$ \\
\hline & & & $\mathrm{CFU} \mathrm{mL} \mathrm{m}^{-1}$ & & & & \\
\hline & & $3.24 \times 10^{8}$ & $3.60 \times 10^{8}$ & $3.92 \times 10^{8}$ & & & \\
\hline & & $\pm 14.6 \%$ & $\pm 0.937 \%$ & $\pm 8.37 \%$ & & & \\
\hline
\end{tabular}

Any two means reported with different letters are significantly different at the $\mathrm{P}=0.05$ level. These statistical comparisons were made within isolate only.

Pantoea agglomerans, Pseudomonas oleovorans, Rahnella aquatilis, Salmonella Typhi, and Serratia proteamaculans. Of these 5 organisms, Omnilyse was the statistical frontrunner only with respect to $R$. aquatilis $(13.8 \pm 2.64$ copies $\mathrm{CFU}^{-1}$ which is a little $<2$-fold to $>3$-fold greater than either Agencourt or High Pure, respectively). Omnilyse was statistically equivalent to the best of the other methods with $P$. agglomerans, P. oleovorans, and S. Typhi. Of all the organisms tested, only $S$. proteamaculans showed a relatively poor apparent extraction efficiency with the Omnilyse procedure $\left(1.18 \pm 0.788\right.$ copies $\mathrm{CFU}^{-1}$ [or $1.60 \pm 0.396$ if culture $\# 1$ is ignored]): assuming 7 copies genome $^{-1}$

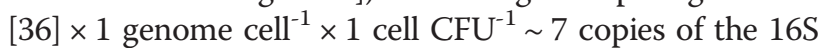
$r$ RNA gene $\mathrm{CFU}^{-1}$, the Omnilyse technique was only $\sim 17-$ 23\% efficient and the Agencourt procedure is about $83 \%$ efficient. Using the same assumptions for $S$. Typhi (e.g., 11 copies of $16 \mathrm{~S} r \mathrm{DNA} \mathrm{CFU}^{-1}$ ) we estimate $>80 \% E E$ for Agencourt and $\sim 60 \%$ for Omnilyse. It is interesting, therefore, that the Gram-positive isolates give what appears to be near-quantitative genomic DNA isolation using Omnilyse but this was not the case for all of the Gram-negative Eubacteria. Because of this latter observation, 
Table 5 Colony forming unit-normalized 16S rDNA copy number for the best extraction protocols (Tables 1, 2 and 3) associated with three biological replicates of various Gram-negative Eubacteria (A-K)

\begin{tabular}{|c|c|c|c|c|c|c|c|}
\hline \multirow[b]{2}{*}{ Gram Neg isolates } & \multirow[b]{2}{*}{ Extraction method } & \multicolumn{5}{|c|}{ Copies 16S rRNA "gene" per CFU } & \\
\hline & & Culture 1 & Culture 2 & Culture 3 & Mean & Stdev & \\
\hline \multirow[t]{6}{*}{ Aeromonas salmonicida } & High Pure & 11.0 & 11.2 & 11.0 & 11.1 & 0.115 & $a$ \\
\hline & Agencourt & 18.4 & 12.6 & 20.5 & 17.2 & 4.09 & $a$ \\
\hline & OmniLyse & 11.8 & 6.73 & 15.3 & 11.3 & 4.31 & $a$ \\
\hline & & & $\mathrm{CFU} \mathrm{mL}^{-1}$ & & & & \\
\hline & & $8.96 \times 10^{8}$ & $9.82 \times 10^{8}$ & $7.21 \times 10^{8}$ & & & \\
\hline & & $\pm 12.7 \%$ & $\pm 16.4 \%$ & $\pm 10.4 \%$ & & & \\
\hline \multirow[t]{6}{*}{ Acinetobacter Iwofii } & High Pure & 4.51 & 3.09 & 2.55 & 3.38 & 1.01 & $a$ \\
\hline & Agencourt & 2.97 & 3.34 & 2.17 & 2.83 & 0.598 & $a$ \\
\hline & OmniLyse & 86.2 & 136 & 81.2 & 101 & 30.3 & $b$ \\
\hline & & & $\mathrm{CFU} \mathrm{mL} \mathrm{m}^{-1}$ & & & & \\
\hline & & $1.68 \times 10^{8}$ & $1.17 \times 10^{8}$ & $1.59 \times 10^{8}$ & & & \\
\hline & & $\pm 10.1 \%$ & $\pm 0.432 \%$ & $\pm 16.4 \%$ & & & \\
\hline \multirow[t]{6}{*}{ Citrobacter freundii } & High Pure & 0.180 & 0.241 & 0.251 & 0.224 & 0.0384 & $a$ \\
\hline & Agencourt & 0.300 & 0.292 & 0.244 & 0.279 & 0.0303 & $a$ \\
\hline & OmniLyse & 25.1 & 20.0 & 17.3 & 20.8 & 3.96 & $b$ \\
\hline & & & $\mathrm{CFU} \mathrm{mL}^{-1}$ & & & & \\
\hline & & $6.42 \times 10^{8}$ & $6.26 \times 10^{8}$ & $6.39 \times 10^{8}$ & & & \\
\hline & & $\pm 7.61 \%$ & $\pm 9.55 \%$ & $\pm 6.99 \%$ & & & \\
\hline \multirow[t]{6}{*}{ Hafnia alvei } & High Pure & 3.36 & 3.58 & 2.28 & 3.07 & 0.696 & $a$ \\
\hline & Agencourt & 2.57 & 5.97 & 4.96 & 4.50 & 1.75 & $a$ \\
\hline & OmniLyse & 12.8 & 7.78 & 8.68 & 9.75 & 2.68 & $b$ \\
\hline & & & $\mathrm{CFU} \mathrm{mL}^{-1}$ & & & & \\
\hline & & $1.62 \times 10^{9}$ & $1.85 \times 10^{9}$ & $1.66 \times 10^{9}$ & & & \\
\hline & & $\pm 15.9 \%$ & $\pm 27.5 \%$ & $\pm 25.5 \%$ & & & \\
\hline \multirow[t]{6}{*}{ Kluyvera ascobata } & High Pure & 5.68 & 4.20 & 3.34 & 4.41 & 1.18 & $a$ \\
\hline & Agencourt & 8.38 & 10.9 & 7.37 & 8.88 & 1.82 & $b$ \\
\hline & OmniLyse & 14.0 & 15.2 & 10.3 & 13.2 & 2.55 & c \\
\hline & & & CFU mL ${ }^{-1}$ & & & & \\
\hline & & $1.12 \times 10^{9}$ & $9.24 \times 10^{8}$ & $1.24 \times 10^{9}$ & & & \\
\hline & & $\pm 17.0 \%$ & $\pm 6.65 \%$ & $\pm 16.1 \%$ & & & \\
\hline
\end{tabular}

Means reported with different lettters are significantly different at the $\mathrm{P}=0.05$ level. These statistical comparisons were made within isolate only.

we hypothesize that some genomic DNA shearing may be occurring for some isolates when using the Omnilyse procedure.

\section{Conclusions}

In this work we have evaluated a dozen commercial bacterial genomic DNA extraction methodologies using 3 biological replicates each of $B t$ (Gram-positive), Ss (Gram-negative), and Ec (Gram-negative). We utilized real time $q \mathrm{PCR}$ quantitation and two specific sets of primers (one for $B t$ and one other against $S s$ and $E c$ ) associated with $16 \mathrm{~S} r \mathrm{RNA}$ gene to determine the number of copies per CFU by comparing the 4 dilutions of unknown target DNA extracts using $q$ PCR in conjunction with 6 dilutions of standards for each primer set. Dilutions of the unknown extract were made in order to determine if any polymerase chain reaction inhibition was apparent since this would result in an evident nonlinear relationship between $C_{\partial j}$ and $\log _{10}\left[0.1^{j}\right]$ and poor $\varepsilon_{\text {unk }}$ values $\left(0.9>\varepsilon_{\text {unk }}>1.1\right)$. We observed such an inhibition in only two extraction procedures (QuickExtract and Labiase). The QuickExtract inhibition was overcome (Figure 1) by purifying the extracted genomic DNA using AmPure magnetic beads with only minor loss of DNA. Based upon statistical analyses of all our results, we determined that the Agencourt Genfind v2 (Beckman 
Table 6 Colony forming unit-normalized 16S rDNA copy number for the best extraction protocols (Tables 1, 2 and 3 ) associated with three biological replicates of various Gram-negative Eubacteria (P-S)

\begin{tabular}{|c|c|c|c|c|c|c|c|}
\hline \multirow[b]{2}{*}{ Gram Neg isolates } & \multirow[b]{2}{*}{ Extraction method } & \multirow[b]{2}{*}{ Culture 1} & \multicolumn{4}{|c|}{ Copies 16S rRNA "gene" per CFU } & \\
\hline & & & Culture 2 & Culture 3 & Mean & Stdev & \\
\hline \multirow[t]{6}{*}{ Pantoea agglomerans } & High Pure & 15.7 & 10.8 & 9.97 & 12.2 & 3.10 & $a$ \\
\hline & Agencourt & 13.2 & 16.2 & 15.2 & 14.9 & 1.53 & $a b$ \\
\hline & OmniLyse & 20.8 & 23.3 & 29.8 & 24.6 & 4.65 & $b$ \\
\hline & & & CFU mL $\mathrm{m}^{-1}$ & & & & \\
\hline & & $5.04 \times 10^{8}$ & $5.03 \times 10^{8}$ & $4.09 \times 10^{8}$ & & & \\
\hline & & $\pm 12.4 \%$ & $\pm 12.6 \%$ & $\pm 10.9 \%$ & & & \\
\hline \multirow[t]{10}{*}{ Pseudomonas oleovorans } & High Pure (TSB) & 38.6 & 30.4 & 24.9 & 31.3 & 6.89 & $a$ \\
\hline & Agencourt (TSB) & 36.7 & 42.3 & 48.9 & 42.6 & 6.11 & $a b$ \\
\hline & OmniLyse (TSB) & 69.9 & 52.4 & 58.1 & 60.1 & 8.93 & $a b$ \\
\hline & OmniLyse (LB) & 73.0 & 120 & 205 & 133 & 66.9 & $b$ \\
\hline & & & CFU mL $\mathrm{mL}^{-1}$ (TSB) & & & & \\
\hline & & $5.21 \times 10^{7}$ & $4.62 \times 10^{7}$ & $5.17 \times 10^{7}$ & & & \\
\hline & & $\pm 7.10 \%$ & $\pm 0.729 \%$ & $\pm 7.82 \%$ & & & \\
\hline & & & $(\mathrm{LB})$ & & & & \\
\hline & & $4.89 \times 10^{7}$ & $2.70 \times 10^{7}$ & $1.89 \times 10^{7}$ & & & \\
\hline & & $\pm 17.1 \%$ & $\pm 4.36 \%$ & $\pm 25.8 \%$ & & & \\
\hline \multirow[t]{6}{*}{ Rahnella aquatilis } & High Pure & 5.15 & 5.43 & 6.28 & 5.62 & 0.588 & $a$ \\
\hline & Agencourt & 7.83 & 8.57 & 7.05 & 7.82 & 0.760 & $b$ \\
\hline & OmniLyse & 16.7 & 13.3 & 11.5 & 13.8 & 2.64 & c \\
\hline & & & $\mathrm{CFU} \mathrm{mL}^{-1}$ & & & & \\
\hline & & $6.04 \times 10^{8}$ & $7.07 \times 10^{8}$ & $8.13 \times 10^{8}$ & & & \\
\hline & & $\pm 16.0 \%$ & $\pm 13.5 \%$ & $\pm 16.1 \%$ & & & \\
\hline \multirow[t]{6}{*}{ Salmonella Typhi } & High Pure & 3.17 & 3.81 & 4.69 & 3.89 & 0.763 & $a$ \\
\hline & Agencourt & 10.7 & 8.10 & 8.48 & 9.09 & 1.40 & $a$ \\
\hline & OmniLyse & 7.50 & 5.71 & 6.39 & 6.53 & 0.904 & $a b$ \\
\hline & & & $\mathrm{CFU} \mathrm{mL}^{-1}$ & & & & \\
\hline & & $8.98 \times 10^{8}$ & $7.70 \times 10^{8}$ & $7.13 \times 10^{8}$ & & & \\
\hline & & $\pm 0.750 \%$ & $\pm 3.72 \%$ & $\pm 2.60 \%$ & & & \\
\hline \multirow[t]{6}{*}{ Serratia preteamaculans } & High Pure & 3.24 & 3.35 & 6.57 & 4.39 & 1.89 & $b$ \\
\hline & Agencourt & 5.59 & 5.34 & 6.57 & 5.83 & 0.650 & $b$ \\
\hline & OmniLyse & 0.325 & 1.88 & 1.32 & 1.18 & 0.788 & $a$ \\
\hline & & & $\mathrm{CFU} \mathrm{mL}^{-1}$ & & & & \\
\hline & & $1.33 \times 10^{9}$ & $1.19 \times 10^{9}$ & $1.19 \times 10^{9}$ & & & \\
\hline & & $\pm 12.8 \%$ & $\pm 11.7 \%$ & $\pm 13.4 \%$ & & & \\
\hline
\end{tabular}

Any two means reported with different letters are significantly different at the $\mathrm{P}=0.05$ level. These statistical comparisons were made within isolate only.

Coulter), High Pure PCR Template Prep Kit (Roche Diagnostics), and Omnilyse (Claremont BioSolutions) methods provided the greatest consistent yield of genomic DNA (Tables 1, 2 and 3). Assuming 6-7× 16S rRNA gene copies per genome, between 1 and 3 genomes per cell (mid-log phase) and $100-200(B t)$ or $1-2$ cells $\mathrm{CFU}^{-1}$ (Ss and $E c$ ) and a correction for the diminution of CFU survival on solid media, we project that the quantitative extraction of genomic DNA from these isolates should produce $\sim 1,00016 \mathrm{~S} r \mathrm{DNA}$ copies $\mathrm{CFU}^{-1}$ for $B t$ and 22 to 32 copies $\mathrm{CFU}^{-1}$ for either $S s$ or $E c$. The large number of cells $\mathrm{CFU}^{-1}$ implied by the $\mathrm{Bt}$-Omnilyse results were supported by CFU-normalized OD data (100 to 122 cells $\mathrm{CFU}^{-1}$ ). Taking this into account, the Omnilyse procedure appeared to provide near-quantitative extraction of genomic DNA for many of these isolates. These three 
consistently best-performing methods (Agencourt, High Pure, Omnilyse) were assessed (Tables 4, 5 and 6) using 5 additional Gram-positive isolates and 9 Gram-negative species using a set "universal" $16 \mathrm{~S} r \mathrm{DNA}$ primers. The best overall method was found to be Omnilyse inasmuch as $72 \%$ of the isolates tested gave the greatest recovery with this procedure. For 17\% of these isolates, Omnilyse was statistically equivalent to the best method (Agencourt) for these particular organisms. In $20 \%$ of the isolates tested (S. pneumoniae, A. salmonicida, and S. Typhi), the Omnilyse extraction procedure provided less genomic DNA than (but not statistically significant) the best method. However, one of the Gram-negative isolates (S. proteamaculans; < 2 copies $\mathrm{CFU}^{-1}$ ) showed the Omnilyse method was not as efficient as the other methods which might argue that this technique is damaging the DNA in some species.

\section{Additional files}

Additional file 1: Ss copies $16 \mathrm{~S}$ rDNA per CFU.

Additional file 2: Analysis of Variance and Other Statistical Expressions.

Competing interests

The authors declare that they have no competing interests.

\section{Authors' contributions}

Conceived and designed the experiments: PI. Performed the experiments: LN, PI. Analyzed the data: PI. Contributed reagents/primer design/expertise in various instrumentation: C-YC, YH, GP, AG. Wrote the paper: PI, LN. All authors read and approved the final manuscript.

\section{Acknowledgements}

All funding was from ARS base funds associated with Current Research Information System (CRIS) Project Number 8072-42000-067-00D (Microbial Communities and Interactions and their Impact on Food Safety).

Received: 12 March 2014 Accepted: 16 December 2014

Published online: 31 December 2014

\section{References}

1. Irwin PL, Nguyen L-HT, Chen C-Y, Paoli G: Binding of nontarget microorganisms from food washes to anti-Salmonella and anti-E. coli 0157 immunomagnetic beads: most probable composition of background Eubacteria. Anal Bioanal Chem 2008, 391:525-536.

2. Staley JT, Konopka A: Measurement of in situ activities of nonphotosynthetic microorganisms in aquatic and terrestrial habitats. Annu Rev Microbiol 1985, 39:321-346.

3. Handelsman J: Metagenomics: application of genomics to uncultured microorganisms. Microbiol Mol Biol R 2004, 68:669-685.

4. Stewart EJ: Growing unculturable bacteria. J Bacteriol 2012, 194:4151-4160

5. Irwin P, Reed S, Brewster J, Nguyen L, He Y: Non-stochastic sampling error in quantal analyses for Campylobacter species on poultry products. Anal Bioanal Chem 2013, 405:2353-2369.

6. Thomas T, Gilbert J, Meyer F: Metagenomics - a guide from sampling to data analysis. Microb Inform Exp 2012, 2:3.

7. Boucher SN, Slater ER, Chamberlain AHL, Adams MR: Production and viability of coccoid forms of Campylobacter jejuni. J Appl Bacteriol 1994, 77:303-307.

8. He Y, Chen C-Y: Quantitative analysis of viable, stressed and dead cells of Campylobacter jejuni strain 81-176. Food Microbiol 2010, 27:439-446.

9. Vandeventer PE, Weigel KM, Salazar J, Erwin B, Irvine B, Doebler R, Nadim A, Cangelosi GA, Niemz A: Mechanical disruption of lysis-resistant bacterial cells by use of a miniature, low-power, disposable device. J Clin Microbio/ 2011, 49:2533-2539.

10. Dart RK: Microbiology for the Analytical Chemist. Cambridge, UK: The Royal Society of Chemistry; 1996:159.

11. Perry JJ, Staley JT: Microbiology: Dynamics and Diversity. Harcourt Brace, Ft. Worth: Saunders College Publishing: 1997:911.

12. de Lipthay JR, Enzinger C, Johnsen K, Aamand J, Sørensen SJ: Impact of DNA extraction method on bacterial community composition measured by denaturing gradient gel electrophoresis. Soil Biol Biochem 2004, 36:1607-1614.

13. Moore E, Arnscheidt A, Krüger A, Strömpl C, Mau M: Simplified protocols for the preparation of genomic DNA from bacterial cultures. Molecular Microbial Ecology Manual 2004, 1.01(2nd Edition):3-18.

14. Niwa T, Kawamura Y, Katagiri Y, Ezaki T: Lytic enzyme, labiase for a broad range of Gram-positive bacteria and its application to analyze functional DNA/RNA. J Microbiol Meth 2005, 61:251-260.

15. Zhang L, Foxman B, Gilsdorf JR, Marrs CF: Bacterial genomic DNA isolation using sonication for microarray analysis. Biotechniques 2005, 39:640-644.

16. Burke C, Kjelleberg S, Thomas T: Selective extraction of bacterial DNA from the surfaces of macroalgae. Appl Environ Microbiol 2009, 75:252-256.

17. Moré MI, Herrick JB, Silva MC, Ghiorse WC, Madsen EL: Quantitative cell lysis of indigenous microorganisms and rapid extraction of microbial DNA from sediment. Appl Environ Microbiol 1994, 60:1572-1580.

18. Miller DN, Bryant JE, Madsen EL, Ghiorse WC: Evaluation and optimization of DNA extraction and purification procedures for soil and sediment samples. Appl Environ Microbiol 1999, 65:4715-4724.

19. Yang J-L, Wang M-S, Cheng A-C, Pan K-C, Li C-F, Deng S-X: A simple and rapid method for extracting bacterial DNA from intestinal microflora for ERIC-PCR detection. World J Gastroentero 2008, 14:2872-2876.

20. Shahriar M, Haque R, Kabir S, Dewan I, Bhuyian MA: Effect of proteinase-K on genomic DNA extraction from Gram-positive strains. Stamford J Pharm Sci 2011, 4:53-57.

21. Quigley L, O'Sullivan O, Beresford TP, Ross RP, Fitzgerald GF, Cotter PD: A comparison of methods used to extract bacterial DNA from raw milk and raw milk cheese. J Appl Microbiol 2012, 113:96-105.

22. Rantakokko-Jalava K, Jalava J: Optimal DNA isolation method for detection of bacteria in clinical specimens by broad-range PCR. J Clin Microbiol 2002, 40:4211-4217.

23. Marmur J: A procedure for the isolation of deoxyribonucleic acid from micro-organisms. J Mol Biol 1961, 3:208-218.

24. Marouani-Gadri N, Augier G, Carpentier B: Characterization of bacterial strains isolated from a beef-processing plant following cleaning and disinfection - Influence of isolated strains on biofilm formation by Sakaï and EDL 933 E. coli 0157:H7. Int J Food Microbiol 2009, 133:62-67.

25. Irwin PL, Nguyen L-HT, Chen C-Y, Uhlich GA, Paoli GC: A method for correcting standard-based real-time PCR DNA quantitation when the standard's polymerase reaction efficiency is significantly different from that of the unknown's. Anal Bioanal Chem 2012, 402:2713-2725.

26. Schnell S, Mendoza C: Enzymological considerations for a theoretical description of the quantitative competitive polymerase chain reaction (QC-PCR). J Theor Biol 1997, 184:433-440.

27. Steele RGD, Torrie JH: Principles and Procedures of Statistics. New York: McGraw-Hill Book Co., Inc; 1960:88-98. 132-137.

28. Zar JH: Biostatistical Analysis. Upper Saddle River: Prentice Hall; 1999:210-214.

29. Cottrell MT, Kirchman DL: Community composition of marine bacterioplankton determined by $16 \mathrm{~S}$ rRNA gene clone libraries and fluorescence in situ hybridization. Appl Environ Microbiol 2000, 66:5116-5122.

30. Ririe KM, Rasmussen RP, Wittwer CT: Product differentiation by analysis of DNA melting curves during the polymerase chain reaction. Anal Biochem 1997, 245:154-160.

31. Nadkarni MA, Martin FE, Jacques NA, Hunter N: Determination of bacterial load by real-time PCR using a broad-range (universal) probe and primers set. Microbiol 2002, 148:257-266.

32. Shain $E B$, Clemens JM: A new method for robust quantitative and qualitative analysis of real-time PCR. Nucleic Acids Res 2008, 36:e91.

33. Chen C-Y, Nace G, Irwin P: A $6 \times 6$ drop plate method for simultaneous colony counting and MPN enumeration of Campylobacter jejuni, Listeria monocytogenes, and Escherichia coli. J Microbiol Meth 2003, 55:475-479.

34. Bassil NV, Muminova M, Njuguna W: Microsatellite-based fingerprinting of western blackberries from plants, IQF berries and puree. Acta Hortic 2010, 859:73-80. 
35. Dumont F, Marechal P-A, Gervais P: Involvement of two specific causes of cell mortality in freeze-thaw cycles with freezing to $-196^{\circ} \mathrm{C}$. Appl Environ Microbiol 2006, 72:1330-1335

36. Pei AY, Oberdorf WE, Nossa CW, Agarwal A, Chokshi P, Gerz EA, Jin Z, Lee P, Yang L, Poles M, Brown SM, Stotero S, DeSantis T, Brodie E, Nelson K, Pei Z: Diversity of $16 \mathrm{~S}$ rRNA genes with individual prokaryotic genomes. Appl Environ Microbiol 2010, 76:3886-3897.

37. Collins MD, Wallbanks S, Lane DJ, Shah J, Nietupski R, Smida J, Dorsch M Stackerbrandt E: Phylogenetic analysis of the genus Listeria based on reverse transcriptase sequencing of 16S rRNA. Int I Syst Bacteriol 1991, 41:240-246.

38. Stackebrandt E, Jones D: The genus Brochothrix. Prokaryotes 2006, 4:477-491.

39. Sherrat DJ: Bacterial chromosome dynamics. Science 2003, 301:780-785. 